Universidad de Lima

Escuela de Posgrado

Maestría en Derecho Empresarial

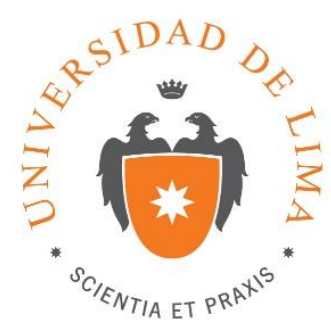

\title{
LA RESPONSABILIDAD NOTARIAL A PROPÓSITO DEL ARTÍCULO 55 DE LA LEY DEL NOTARIADO
}

Trabajo de investigación para optar el Grado Académico de Maestro en Derecho

Empresarial

\section{Juan Miguel Carhuamaca Soto}

Código 20060217

Asesor: Maximiliano Salazar Gallegos

$$
\text { Lima - Perú }
$$

Noviembre 2017 


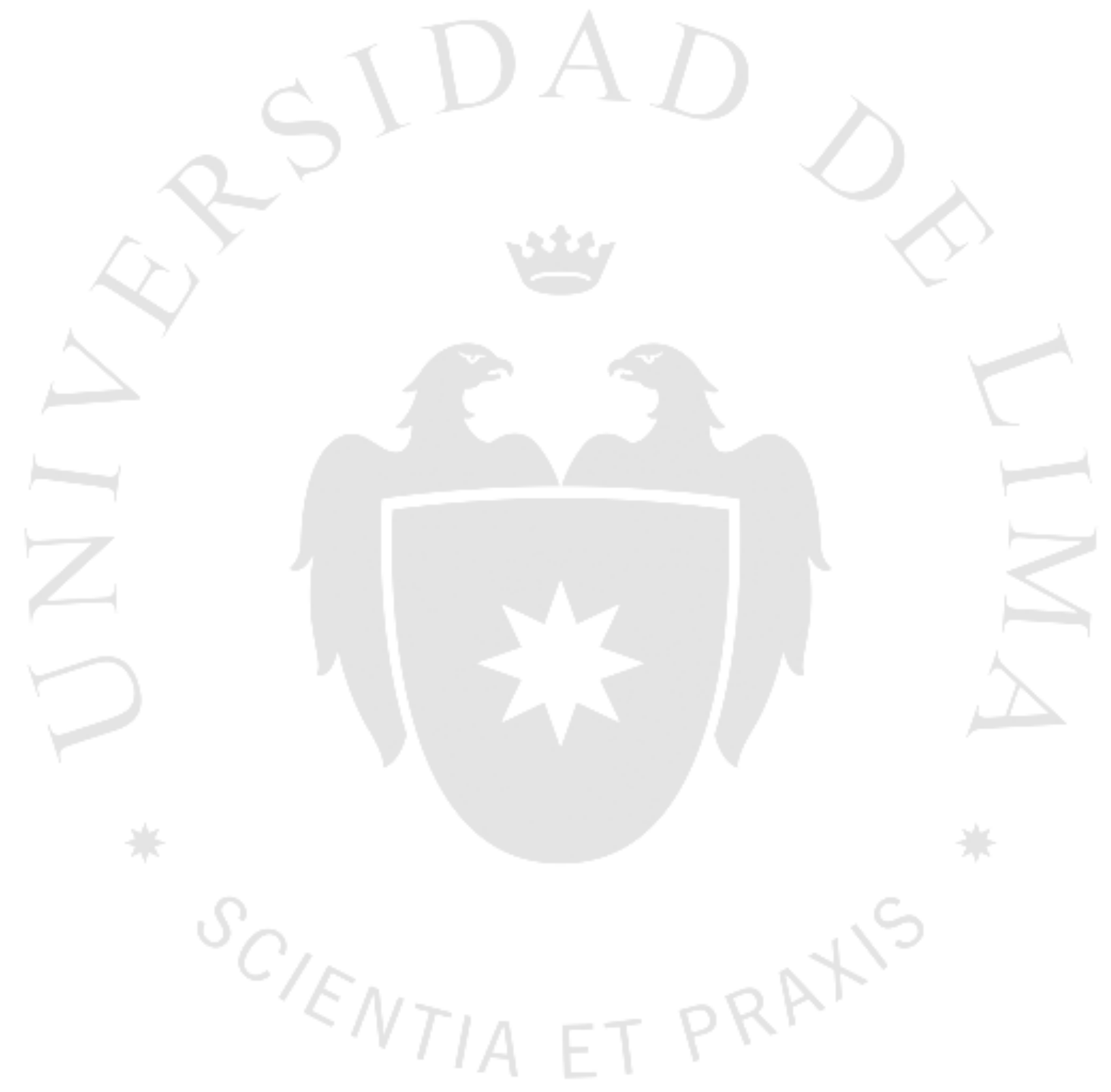




\section{LA RESPONSABILIDAD NOTARIAL A PROPÓSITO DEL ARTÍCULO 55 DE LA LEY DEL NOTARIADO}




\section{TABLA DE CONTENIDOS}

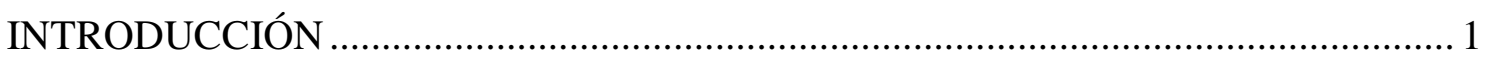

CAPÍTULO 1: ASPECTOS GENERALES DE LA FUNCIÓN NOTARIAL ................. 3

1.1. Marco conceptual de la Función Notarial ...............................................................

1.2. Características de la función Notarial.................................................................. 4

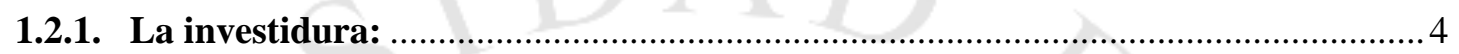

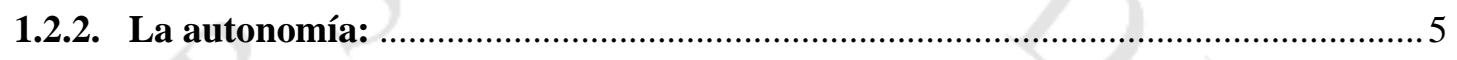

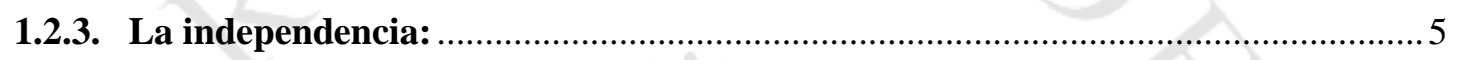

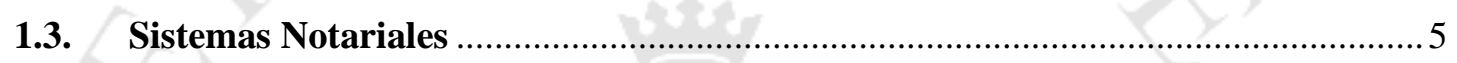

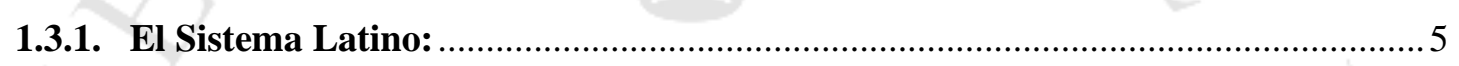

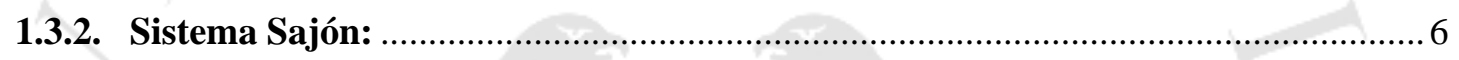

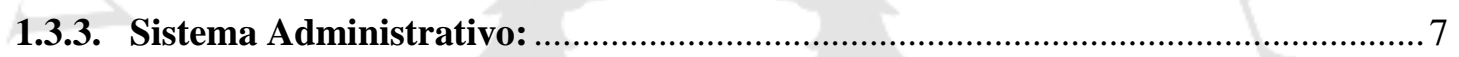

1.3.4. Diferencias entre el notario latino y el notariado sajón:........................................ 7

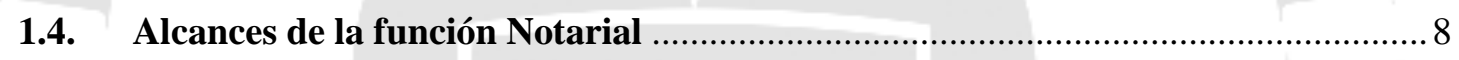

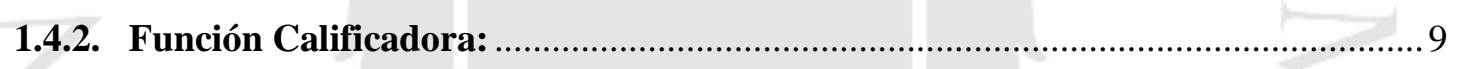

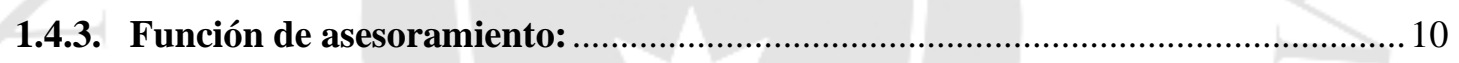

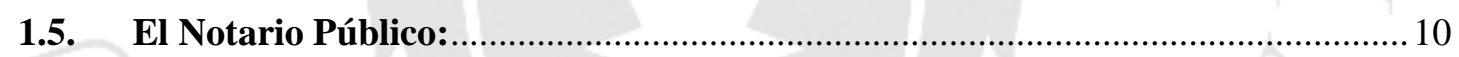

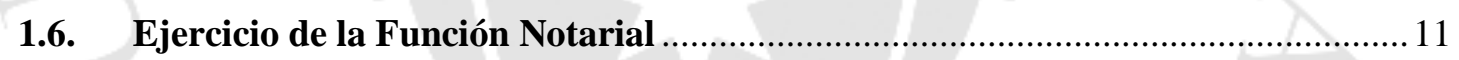

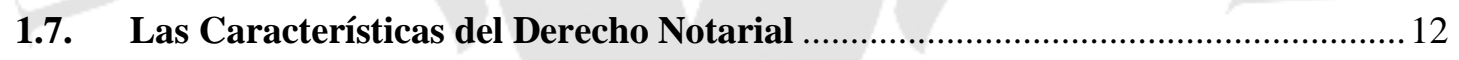

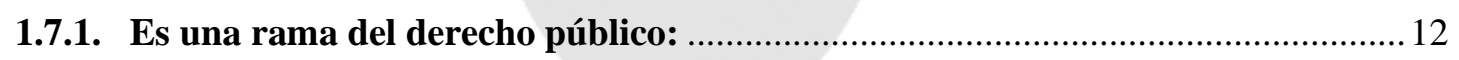

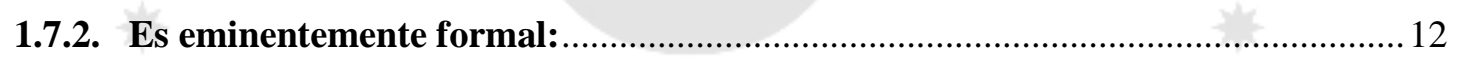

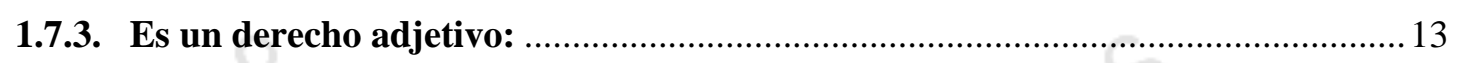

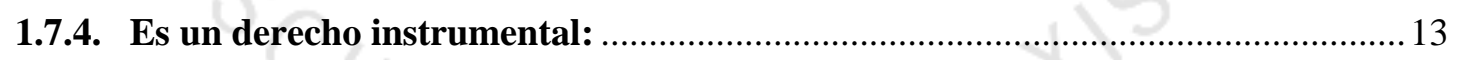

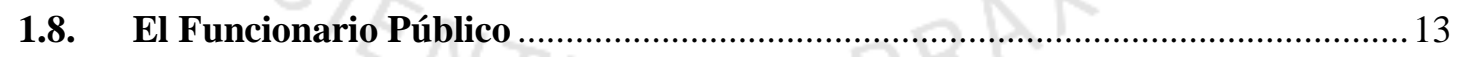

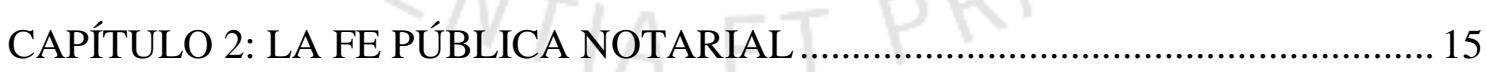

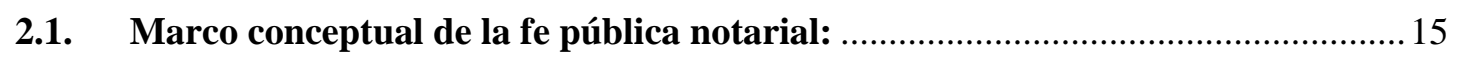

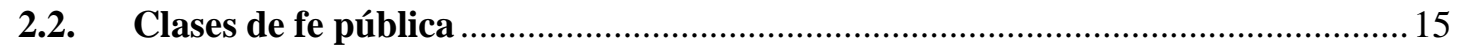

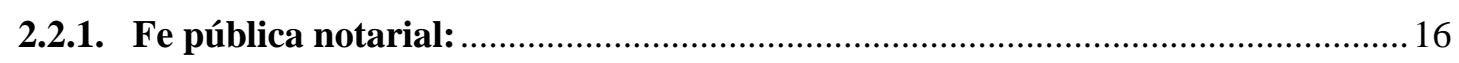

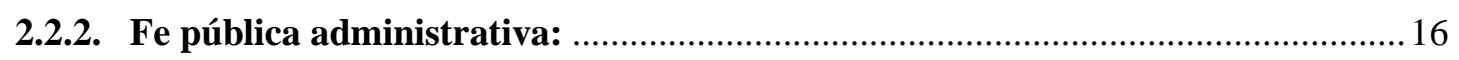

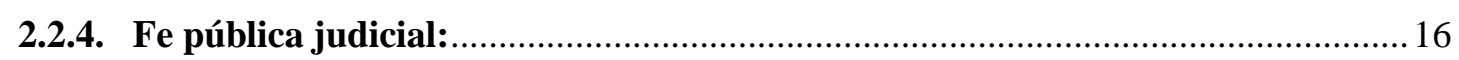

CAPÍTULO 3: LA RESPONSABILIDAD NOTARIAL ........................................... 17

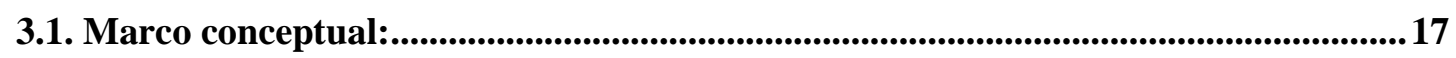


3.2. La función objetiva y subjetiva del ejercicio de la función notarial: .17

3.2.1. Función Objetiva: .18

3.2.2. Función Subjetiva: .18

3.2.3. La responsabilidad civil respecto de las funciones atribuidas al dependiente, a propósito de las modificatorias propuestas en el artículo 55 de la Ley del Notariado............................................................19

3.3. Responsabilidad Civil del Notario .19

3.4. Responsabilidad Civil Extracontractual del Notario, apropósito de la intervención de sus representantes de hecho, como hecho personalísimo del mismo: ...26

3.5. ¿El artículo 55 de la Ley del Notariado, una eximente de responsabilidad?: .27 


\section{INTRODUCCIÓN}

La labor Notarial en el tiempo, ha tenido un rol importante en el ejercicio de sus funciones, formalizando la voluntad de las partes y brindando celeridad a cada trámite solicitado. El beneficio es tal, que frente a los prolongados plazos judiciales y la carga procesal a la que estamos acostumbrados, en el marco del consenso y la plena voluntad; el Notario, es un eficiente profesional del Derecho quien mediante la Fe pública que le es conferida por el Estado, da fe los acuerdos de las partes, en el marco de las atribuciones conferidas por el Decreto Legislativo $N^{\circ} 1049$ (Ley del Notariado) y su Reglamento, disposición normativa que citaremos renuentemente para lo cual y en lo sucesivo denominaremos solamente "La Ley".

Por historia, sabemos que en la antigüedad, la manifestación de voluntad siempre fue oral, y no existió un Notario; toda manifestación y/o hecho estaba contenida en testigos, de eventos de gran acontecimiento. Conforme a ello, el hablar del inicio de la función Notarial, es remontarnos en el caso Peruano y con la llegada de los Españoles, a aquellos cronistas que dejaban constancia de los hechos que acontecían en la época, los mismos que datan en su relación más próxima, el inicio de la función Notarial. En la actualidad, las escrituras de aquellos cronistas, por historia; conocemos han sido archivadas en el Archivo General de la Nación. El escribir u acontecimiento y mantenerlo en el tiempo, conllevan a vincular mediante un rol aparente al Notario y a la Fe Pública.

En la actualidad, no solo el Notario va adquiriendo un rol protagónico muy importante en nuestra sociedad, sino además la gran responsabilidad que este tiene frente a los actos celebrados en su presencia, adquiriendo mayor responsabilidad y cuidado. Una mala formalización en el acuerdo de la voluntad de las partes, podría acarrear sanciones tanto administrativas, ante el Consejo disciplinario del Notariado, Civiles y/o Penales; de donde la sanción más grave podría significar inclusive la destitución del cargo, que le fuere conferido por el Ministerio de Justicia.

Sobre lo mencionado precedentemente y apropósito del rol protagónico del Notario y la gran responsabilidad a su cargo, el presente trabajo gira en torno a la redacción del art. 55 de la Ley Notariado, el mismo que actúa como un eximente de 
responsabilidad, a los hechos vinculados dentro de la función notarial y de donde el Notario haya sido inducido a error en el momento de dar fe a la identidad de los otorgantes. Es el caso, que para el ejercicio personal de la función Notarial, el Notario no excluye la colaboración de dependientes del despacho notarial para realizar actos complementarios o conexos que coadyuven a su desarrollo, por lo que resulta imprescindible determinar los límites de la responsabilidad notarial, a propósito de la intervención de terceros y/o dependientes que en el ejercicio de las funciones a su cargo,

La precitada norma, es el único artículo que exime de responsabilidad al Notario, siempre que haya sido inducido a error por la actuación maliciosa de los otorgantes. Dicho esto, resulta oportuno considerar que para el desarrollo de la función Notarial, el D.L. 1049 otorga la posibilidad de Para lo cual será importante definir los límites de responsabilidad Notarial, comentando brevemente como el mismo, ejerce la función pública en su oficio notarial.

Por último, es importante señalar que si bien podemos hablar de una responsabilidad Civil, Penal y/o administrativa del Notario, dentro de las sanciones disciplinarias, existe un accionar directo por parte del Colegio de Notarios de Lima, pudiendo solicitar la suspensión temporal del cargo y/o la destitución como sanción más grave, frente a un procedimiento disciplinario sancionador. 


\section{CAPÍTULO 1: ASPECTOS GENERALES DE LA FUNCIÓN NOTARIAL}

\subsection{Marco conceptual de la Función Notarial}

Por estudio sabemos que el derecho notarial, no solo es una rama del derecho público, sino además en la interacción de las demás áreas del derecho, encontramos el estudio en su conjunto con los diferentes sistemas notariales, es por ello, que como lo han referido diversos autores en la materia, si hablamos de la función notarial, podemos subsecuentemente hablar de responsabilidad notarial, procesos notariales, instrumentos públicos notariales protocolares o extra protocolares, entre otros temas vinculados al derecho notarial. Entendiendo que nuestro sistema notarial es el sistema latino, es oportuno precisar en materia conceptual, algunos aspectos:

Sotomayor, Bernos (1991) señala que el Sistema notarial Latino tiene como eje o protagonista al notario, considerado como un profesional del derecho que en forma imparcial e independiente, ejerce una función pública, consistente en la formación, conservación, reproducción y autentificación del documento notarial, incluyéndose dentro de su alcance la certificación de hechos. (p.20)

El notario latino tiene, pues una doble misión: dar fe y dar forma. Es una creencia equivocada y simplista de ver la función notarial como un mero acto de certificación de firmas o de reproducciones fotostáticas. Es una parte de la función, es cierto. Pero la facultad autentificadora, de dar fe, es intrínseca al notario y se manifiesta en todo campo de su actuación, inclusive en su labor conformadora de instrumentos públicos. Pero es en esta misión del notario de dar forma, de hacer instrumentos públicos, donde se hacen evidentes todos los atributos que caracterizan al notario latino.

La función notarial es una actividad profesional muy singular. Su facultad fedante nacida de la Ley, que impone a la sociedad y al Estado una presunción de veracidad que sólo puede ser vencida judicialmente, lo convierte en una autoridad.

El notario latino tiene el deber de averiguar la verdadera voluntad de las partes, brindar su asistencia profesional y redactar el instrumento, ya se para dar nacimiento al 
acto o contrato o para darle una mejor forma probatoria, según sea el caso. (Sotomayor, Bernos 1991, p. 22-23)

Por su parte Tambini, Mónica, refiere que la función notarial [son] el conjunto de normas legislativas, reglamentarias, usos, decisiones jurisprudenciales y doctrinas que rigen la función notarial y el instrumento público notarial constituye el Derecho Notarial $^{1}$. (Citado por Tambini, Mónica 2014: p. 21)

Núñez Lagos (1986), señala: El derecho notarial se encuentra dentro del derecho de las formas, pues pertenece a aquellas formas escritas - documentales - que requieren la intervención de un funcionario llamado notario. (p.14)

Dentro del desenvolvimiento de la función pública del notario, advertimos que el mismo otorga seguridad jurídica a los actos y/o hechos solicitados por las partes, materializándose la formalización de dichos acuerdos, en la suscripción de un instrumento público. Bajo el formalismo enunciado, es que podemos advertir que el notario abarca una responsabilidad tuitiva, propia de su función de letrado; así como la del cargo que le es conferido por el Ministerio de Justicia, como notario público. Esa funcionabilidad combinada, es la clara evidencia de la existencia de la función notarial vinculada con los demás sistemas notariales, que en el desarrollo de los puntos enunciados como índice, desarrollaremos con mayor precisión.

\subsection{Características de la función Notarial}

La función notarial se ve envestida de características inherentes al cargo que realizan, para lo cual citando al Dr. Barragán, podemos sostiene que la función notarial denota con precisión las siguientes:

\subsubsection{La investidura:}

Sotomayor, Bernos (1991) señala a la investidura en la calidad especial que adquiere el notario al tomar la posesión de cargo, antecedida del nombramiento o designación y de la confirmación, calidad que lo autoriza para usar legalmente el título de notario, para

\footnotetext{
${ }^{1}$ Definición expuesta en el Tercer Congreso de la Unión Internacional del Notariado Latino, realizado en Paris (1954). Cfr. Gattari, Carlos Nicolás, Manual de derecho notarial, reimpresión de la primera edición [1998], Buenos Aires, Depalma, 1992, p. 379.
} 
ejercer sus funciones dentro del territorio de su jurisdicción, y lo habilita como depositario y guardián de la fe pública (p. 8)

\subsubsection{La autonomía:}

Barragán 1979 respecto de la autonomía notarial, declara que la actuación del notario se desarrolla conforme a su propio criterio profesional dentro del marco señalado por la ley; en concreto, su radio de acción no fija ninguna autoridad ni funcionario superior alguno; las leyes le señalan la órbita de su trabajo, y son los particulares quieres (...) escogen el notario que habrá de actuar en casa caso (...) Pero es oportuno advertir que la autonomía no significa irresponsabilidad, porque el notario está sometido al régimen legal general, conforme al cual pueden deducírsele especiales responsabilidades tanto civiles como penales, además al régimen disciplinario correspondiente. (p. 9)

\subsubsection{La independencia:}

(...)Significa que el [el notario] está colocado en condiciones tales de autoridad y respetabilidad que lo habiliten para ejercer sus funciones con altura, por encima de los intereses personales, de grupo o políticos, o de cualquiera otra índole semejante (...) (Citado por Villavicencio Miguel, 2012, p. 23)

\subsection{Sistemas Notariales}

En el Mundo existen 3 sistemas distintos del Derecho Notarial: "El notariado latino, Sajón y Administrativo", Tambini Mónica (2014), detalla lo siguiente:

El sistema que tenemos nosotros es el derecho romano germánico que llegó con el código napoleónico y se le llamaba el "Notariado Latino".

\subsubsection{El Sistema Latino:}

El notariado latino está basado claramente en un derecho codificado, donde la ley es su principal fuente y las demás fuentes tradicionalmente reconocidas ocupan un lugar secundario. (...) 
Por estudio y por lo regulado en la propia Ley, podemos comentar que siendo el notariado latino nuestro sistema, a su vez el sistema más extendido en el mundo, algunas de sus características fundamentales para el ejercicio del cargo, son las siguientes:

a) Que el notario sea abogado y una persona especialmente capacitada para serlo.

b) Que el notario redacte los instrumentos y los guarde (Cuando son instrumentos públicos), y lo devuelve cuando no es necesario retenerlo, obligándose previamente a leer los documentos que realizan las partes y la obligación de identificar a las personas.

c) El Notario no puede ejercer otra función que la función Notarial.

Este sistema es aquel que rige en los países miembros de la Unión Internacional del Notariado Latino (UINL) y muchos otros más.

La labor del notario en estos países se constituye en una necesidad pues otorga garantía de autenticidad, imparcialidad y seguridad a los ciudadanos, cumpliendo en ese sentido una doble misión: dar fe y dar forma (...). (p. 40).

\subsubsection{Sistema Sajón:}

El notariado de tipo sajón está basado tradicionalmente en la jurisprudencia y la costumbre; los precedentes son de cumplimiento obligatorio y la prueba por excelencia es la testimonial.

Está muy encapsulado en países como EEUU de América, nueva Zelanda y Japón, siendo algunas características relevantes las siguientes:

a) El notario no tiene por qué ser abogado, paga un derecho y le dan el puesto por determinado tiempo por su buena conducta.

b) El Notario es simple legalizador de firmas, puede ser cualquier persona, solo debe mostrar buena conducta.

c) En este sistema el Notario no vive de este trabajo, por lo que puede ejercer otras labores paralelas.

d) Pueden existir miles de notarios, no existiendo restricción alguna. 
e) No existe un horario de trabajo que cumplir.

La especial formación del derecho inglés, su origen consuetudinario, la excepcional duración en el tiempo de sus leyes, la eficacia normativa de la jurisprudencia y el original sistema de contratación basado, no en un criterio formal, sino causalista (ya que sin la existencia de la consideración la que da fuerza obligatoria a los contratos), ha dado lugar a un especial tipo de notario totalmente distinto al del tipo latino. (...) (p.43)

La tratativa regulada en este sistema, se ve plenamente orientada a una sola función de certificador, limitando las responsabilidades generales y enunciadas en las características del notariado latino, siendo este último, quien lleva una carga y responsabilidad mayor, en atención a las facultades inherentes a su cargo.

\subsubsection{Sistema Administrativo:}

Propio de los países socialistas, parten del concepto de la sociedad socialista, y el derecho, mientras exista, subordina la legalidad a la ideología política. No obstante, la formación jurídica que debe tener el notario para acceder a este cargo, no pasa de ser un empleado público y, por eso, se le denomina "notario de estado", el cual está sometido, jerárquica, disciplinario y funcionalmente a los intereses de la política socialista (...)

Conforme el Balotario Desarrollado para los concursos públicos de méritos para el acceso a la función notarial, algunas características relevantes son las siguientes:

a) El Notario es nombrado por el Estado en cualquier momento, y realiza las labores que se le confiere, puede ejercer la función mientras se mantenga en el cargo, pues puede ser destituido, no hay seguridad en el cargo.

b) El personal y los implementos para desempeñar el cargo le pertenecen al Estado.

c) Este sistema tiene muchas desventajas, pues restringe el derecho profesional.

Lo que se refiere a la independencia e imparcialidad que debe tener todo buen notario están ausentes; el notario como dependiente ejerce también otras funciones en forma paralela, como administrativas y aún judiciales. (p. 44)

\subsubsection{Diferencias entre el notario latino y el notariado sajón:}


Por lo expuesto, en efecto concordamos con lo descrito por la Dra. Tambini Mónica (2014), [en donde, mientras que] el notariado latino está basado en un derecho codificado, en el que la ley es su principal fuente, para el sistema sajón lo es la jurisprudencia y la costumbre.

Otra de las diferencias del notariado latino, es que la prueba por excelencia es la prueba documental, mientras para el notariado sajón es la testimonial.

En cuanto a la función notarial, en el latino, que es de origen romano germánico, es más amplia y trascendente de lo que resulta ser en los países de derecho sajón, donde la función notarial es más limitada y de menor gravitación. (p. 45)

\subsection{Alcances de la función Notarial}

Por un lado Mercedes de la Puente (2007), en atención y considerando el aporte en el tema enunciado, que otorga el Dr. Mixán Mass, detalla que las dimensiones de la función notarial, se extienden en ser:

Óntica: Supone considerar que aquello que es objeto de la fe notarial es una realidad existencial y objetiva, concreta y por lo tanto, sujeta a verificación de vista del Notario. Esa realidad verificable la constituye el suceso, el acto, etc., así como la identidad y la capacidad jurídica del usuario de la fe pública y la necesaria constatación de si este actúa con libertad, voluntad y conocimiento de lo que quiere.

Epistemológica: "Se concreta en tanto le es exigible al Notario aplicar conocimientos rigurosamente especializados y actualizados que garanticen eficiencia y eficacia en el otorgamiento de la fe pública notarial”.

Deontológica: "El desempeño de la función notarial implica la observancia del deber ser jurídico, en especial del deber ser previsto por la constitución y las prescripciones jurídicas que regulan la función notarial, sin perjuicio de la observancia de las demás normas jurídicas que eventualmente resulten concurrentes. (...) 
Axiológica: "La observancia del deber ser jurídico en la función notarial ha de estar inescindiblemente vinculada a la finalidad, esto es, al hecho que los actos notariales estén imbuidos de los valores éticos. De esta forma, se debe poder juzgar sin dificultad alguna que tal o cual acto notarial es honesto, justo, auténtico, veraz e imparcial. Así mismo el notario debe estar atento para evitar que el usuario le sorprenda y lo utilice para fones o consecuencias que atenten contra principios éticos fundamentales como por ejemplo dar fe de cláusulas leoninas, legalizar pactos manifiestos o encubiertos de intereses usuarios, posibilitar la generación de derechos de expectaticios sin la debida garantía o con garantía fáctica y otros casos similares" (p. 49)

El notario público en el ejercicio de sus funciones, tiene la obligación de prever efectos negativos entre las relaciones jurídicas formadas por las partes. Calificando la documentación que tiene a la vista y asesorando a las partes contratantes en todo momento. Dicho esto, compartimos lo señalado por la Dra. Tambini (2014), [detallando] que la función notarial no se restringe a dar fe de los actos que ante el notario se celebran. Su actuación es más amplia de lo que aparenta, debiendo resaltarse dentro de sus alcances, las siguientes funciones:

\subsubsection{Función Preventiva:}

La función notarial prevé la existencia de un conflicto. La intervención del Notario ocupa un rol muy importante, en atención que su disposición tiene lugar con anterioridad a la existencia de un conflicto; dejando constancia en adelante y a través de los jurídicos y contratos elevados a Escritura Pública, que las partes que generen posteriores discrepancias.

\subsubsection{Función Calificadora:}

Entre las actividades funcionales del notario se encuentra la de encuadrar los hechos a las normas jurídicas. El notario determina la relación de derecho que corresponde a los hechos que se presentan. Recibe, interpreta, investiga y da forma legal a la voluntad de las partes. Así, el notario es creador del derecho. Los documentos autorizados por él generan presunción de legalidad. La intervención notarial beneficia a los otorgantes y a la comunidad al controlar la licitud del negocio instrumentado. 


\subsubsection{Función de asesoramiento:}

El asesoramiento permite que las partes otorgantes expresen adecuadamente su voluntad, mediante un encuadre jurídico del negocio. El notario brinda asesoramiento, lo que permite a las partes comprender la naturaleza y efectos o consecuencias jurídicas del acto que van a celebrar ante él. Es, por tanto, función notarial instruir a los otorgantes sobre sus alcances, lo que genera seguridad en las transacciones y, en consecuencia, en la sociedad. (p. 73)

El asesoramiento notarial es aquel que permitirá el trato especializado que tiene el notario con los particulares, permitiendo que las partes contratantes puedan entender las relaciones jurídicas a formalizar sus voluntades, con la confianza que el notario otorga, a fin de otorgar la seguridad jurídica necesaria.

\subsection{EI Notario Público:}

(...) Es el profesional del derecho que está autorizado para dar fe de los actos y contratos que ante él se celebran. Para ello formaliza la voluntad de los otorgantes, redactando los instrumentos a los que confiere autenticidad, conserva los originales y expide los traslados correspondientes.

Su función también comprende la comprobación de hechos y la tramitación de asuntos no contenciosos previstos en las leyes de la materia. (Art. 3 del D. L. 1049).

(...) Es el profesional del derecho, encargado por delegación del Estado, de una función pública consistente en recibir y dar forma a la voluntad de las partes, redacta los instrumentos adecuados a ese fin, les confiere autenticidad, conserva los originales y expide traslados que dan fe de su contenido. Su función también comprende la comprobación de hechos y tramitación de asuntos no contenciosos. (Art. 4 del Reglamento de la Ley del Notariado).

Giménez Arnau, define al notario como un profesional del derecho que ejerce una función pública para robustecer con una presunción de verdad, los actos que interviene, para colaborar en la formación correcta del negocio jurídico y para solemnizar y dar forma legal a los negocios jurídicos privados y de cuya competencia solo por razones 
históricas están sustraídos los actos de la llamada jurisdicción voluntaria. (Citado por Tambini Mónica 2014: p. 47)

Como lo mencionamos con anterioridad, El Notario tiene una función de autenticación, redacción, solemne (Dar fe) y por el Sistema Latino del emana, es aquel que guarda la documentación original de los actos celebrados por las partes, emitiendo copia de esos actos para las partes interesadas.

Para el desarrollo del ejercicio profesional, la Ley del Notariado prevé en su artículo 25 y 26, la formalización de instrumentos protocolares y extra-protocolares, contando con sellos de seguridad, fojas de escrituras públicas debidamente registrados y numerados, además de la firma inherente por parte del Notario responsable; y por último la existencia de un archivo notarial, que conservará en el tiempo la voluntad de las partes formalizadas.

\subsection{Ejercicio de la Función Notarial}

En nuestro país, El Notario ejerce su función en forma personal, autónoma, exclusiva e imparcial. (Art. 3 del D. L. 1049)

En otros países existen Notarios suplentes, ad hoc, adscritos, etc., a diferencia del Perú como lo menciona el artículo tercero de la Ley, la única función que ocupa este cargo es el propio Notario, siendo autónomo pues no es dependiente de nadie. En algunas instituciones financieras y/o administrativas, a diferencia de la dependencia Notarial, los fedatarios son meros certificadores respecto de un fin específico, siendo dependientes de sus superiores.

La función fedante y formalizadora de instrumentos protocolares y extra protocolares que realiza el notario implica la labor de orientación imparcial a los usuarios a que se refieren los artículos $27^{\circ}$ y $99^{\circ}$ de la Ley, de calificación de la legalidad, del otorgamiento del acto o contrato que se solicita; correspondiéndole, la facultad de solicitar la presentación de requisitos, instrumentos previos o comprobantes que acrediten el cumplimiento de obligaciones tributarias, que sean necesarios para la formalización del acto o contrato. En ningún caso, en su condición de notario está facultado a emitir resoluciones. 
La función cautelar y preventiva que cumple el notario implica que en la facción de los instrumentos públicos notariales cumpla con las regulaciones que rigen para cada uno de los casos. (Art. 5 del Reglamento del De la Ley del Notariado).

De lo expuesto por el reglamento, podemos manifestar que El Notario es exclusivo, pues está impedido de ejercer cualquier otra función a fin de guardar la imparcialidad; a lo que la propia Ley prevé la excepción de que este pueda ejercer labores de docencia universitaria. El Ejercicio del notario se debe a la verdad e imparcialidad, tengamos en cuenta que la responsabilidad del notario es por dolo o culpa.

\subsection{Las Características del Derecho Notarial}

El derecho Notarial resulta ser Formal, Adjetivo, Preventivo y la discusión por parte de la doctrina, por si el Notario ejerce se encuentra dentro del marco de la titularidad de Funcionario Público. La Dra. Tambini Mónica (2014) señala cuatro principales características, cuyos contenidos son los siguientes:

\subsubsection{Es una rama del derecho público:}

Sus normas son de cumplimiento obligatorio para el notario, los individuos y otras instituciones del Estado. El notario ejerce una función pública en representación y por delegación del Estado. La doctrina se divide en dos sectores, ya que algunos dicen que es privado y otros públicos. Partiendo del poder que se le es conferido por el Estado diríamos que hablamos de un orden Público, pero por otro lado es libre de ser escogido por los particulares, el propio notario es quien asume sus costos y necesidades, además que el propio Art. 4 del reglamento del D.L. 1049, aclara que el Notario no es Funcionario Público.

\subsubsection{Es eminentemente formal:}

Las normas del Derecho notarial establecen ciertos procedimientos y requisitos para convertir un documento privado en un instrumento público, lo que garantiza su autenticidad. Le da forma al derecho sustantivo, a través de la manifestación de voluntad de los otorgantes. 


\subsubsection{Es un derecho adjetivo:}

Orienta el sentido de las formas de los actos jurídicos y sus contenidos. Sin embargo, el notario debe también asesorar a los otorgantes en los asuntos propios de la materia sustantiva y no es ajeno a la esencia de los actos jurídicos que se celebran ante él o mediante los documentos que llegan a su conocimiento. Tiene plazos que cumplir y se asimila al derecho procesal civil, regula un procedimiento formal que tiene que ser cumplido para poder lograr algo. Si no tiene vista a un procedimiento bien llevado, podría generar que el instrumento público sea nulo o anulable.

\subsubsection{Es un derecho instrumental:}

El documento o instrumento, sea este público o privado, es la materia con la cual trabaja el derecho notarial. (Tambini Mónica 2014, p.26)

Otras características que podemos resaltar, es que el Derecho Notarial es preventivo; ya que la finalidad de su existencia es dar seguridad a las partes y a los terceros intervinientes, aquellos que tienen acceso al instrumento público. Esta característica se encuentra en poder del Notario. El Notario tiene autonomía lógico estructural y autonomía física.

\subsection{El Funcionario Público}

A lo desarrollado brevemente en el desarrollo del punto anterior, resulta importante señalar que el poder público otorgado al Notario, no lo convierte en Funcionario Público, siendo que el propio reglamento de la Ley del Notariado declara lo siguiente:

(...) El notario es el profesional del derecho encargado, por delegación del Estado, de una función pública consistente en recibir y dar forma a la voluntad de las partes, redacta los instrumentos adecuados a ese fin, les confiere autenticidad, conserva los originales y expide traslados que dan fe de su contenido. Su función también comprende la comprobación de hechos y la tramitación de asuntos no contenciosos previstos en las leyes de la materia. (Art. 4 del Reglamento de la Ley del Notariado). 
El notario no es funcionario público para ningún efecto legal. Al respecto el Dr. Gutierrez Walter (2001), afirma que las razones por las cuales un notario no puede ser considerado como funcionario público:

a) No forma parte del escalafón de la administración.

b) No están sometido a dependencia funcional o subordinación jerárquica.

c) El cliente elige al notario sobre la base de su idoneidad y moralidad, no le es impuesto como el funcionario público

d) El estado no responde por los daños que eventualmente se puedan generar como consecuencia de la actuación del notario.

e) El notario realiza una actividad empresarial, tal como se desprende directamente de las normas tributarias y de libre competencia; y finalmente.

f) La actividad notarial, lo mismo que en cualquier profesión liberal, está sujeta a reglas del mercado. (p.54)

Con lo que la calidad jurídica del Notario es evidente en el propio ejercicio profesional, la forma privada de administración de sus recursos y dependencia. 


\section{CAPÍTULO 2: LA FE PÚBLICA NOTARIAL}

\subsection{Marco conceptual de la fe pública notarial:}

La palabra "Fe", proviene del latín fides, recoge la idea de creencia en todas sus modalidades.

Para Gonzalo de las Casas, la fe pública es presunción legal de veracidad respecto a ciertos funcionarios a quienes la ley reconoce como probos y verdaderos, a quienes faculta para darla a los hechos y convenciones que pasan entre los ciudadanos. (Citado por Tambini, Mónica 2014: p. 36)

En una aceptación técnica, Giménez Arnau define la fe pública como la función específica, de carácter público, cuya misión es robustecer con una presunción de verdad los hechos o actos sometidos a su amparo. (Citado por Tambini, Mónica 2014: p. 36)

Mengual y Mengual propuso una definición de fe pública diciendo que es el asentimiento que con <carácter> de verdad y certeza se presta a lo manifestado por aquellos a quienes el poder público reviste de autoridad asignándole una función. (Citado por Tambini, Mónica 2014: p. 36)

Tambini Mónica (2014), sostiene que la fe pública notarial es pues la certeza, confianza, veracidad y autoridad legítima atribuida al Notario respecto, de los actos hechos y dichos realizados u ocurridos en su presencia, los mismos que tienen por verdaderos, auténticos, ciertos, con toda la fuerza probatoria mientras no se demuestre lo contrario. (p.37)

Debemos entender/a la fe pública, como la confianza y veracidad que le corresponde otorgar al Notario, respecto de las voluntades que este formaliza. Teniendo toda el legajo documentario que prueben de la existencia de los actos.

\subsection{Clases de fe pública}

La fe pública se encuentra atribuida a los Notarios y a funcionarios públicos y no es igual en todos los casos. Con carácter excepcional el Estado atribuye a determinados particulares la potestad de fe, solo para trámites específicos, tales como la legalización 
de firmas en oficinas de la SUNARP. Dicho esto, podemos hablar de fe pública notarial, fe pública administrativa, registral, judicial, entre otras.

\subsubsection{Fe pública notarial:}

Para poder dar fe de los actos y contratos que ante él se celebren. Para ello formaliza la voluntad de los otorgantes, redactando los instrumentos, a los que confiere autenticidad, conserva los originales y expide los traslados correspondientes. La fe pública notarial es la que tiene mayor campo de aplicación en nuestra sociedad. (Facultad atribuida por el art. 2 del D.L. 1049).

\subsubsection{Fe pública administrativa:}

Es la facultad atribuid a los fedatarios de las instituciones públicas poder expedir copias certificadas de hojas de los expedientes administrativos que ante ellos se tramiten. (Art. 41 de la Ley 27444).

\subsubsection{Fe pública registral:}

El reglamento general de los registros públicos, autoriza a los registrados a otorgar copias literales de los títulos archivados, inscritos en mérito al principio de publicidad registral. Concordante a ello conforme al primer párrafo del artículo II del Título Preliminar del Reglamento General de los Registros Públicos, en el cual se establece que el Registro es Público y que la publicidad registral garantiza que toda persona acceda al conocimiento efectivo del contenido de las partidas registrales, y en general, obtenga información del archivo registral.

\subsubsection{Fe pública judicial:}

Son obligaciones y atribuciones genéricas de los Secretarios de Juzgado expedir copias certificadas, previa orden judicial. En mérito a la normativa citada es que Los especialistas judiciales ejercen la fe pública, al expedir las copias certificadas que detentan en los archivos judiciales. (Numeral 13 del artículo 266 del TUO de la Ley Orgánica del Poder Judicial). 


\section{CAPÍTULO 3: LA RESPONSABILIDAD NOTARIAL}

\subsection{Marco conceptual:}

El desarrollo profesional en el ejercicio de la función pública y/o privada, cual fuese el ámbito de su desarrollo; incluyendo el de la función notarial; se encuentra expuesta a una responsabilidad administrativa, Civil y/o Penal, en la medida que exista afectación a terceros sea por dolo o culpa. En el caso específico y siendo que en el presente trabajo de investigación, nos encontramos desarrollando la responsabilidad Notarial, orientada a la regulación descrita en el art. 55 de la Ley de Notariado, es oportuno considerar previamente que en materia de responsabilidad Notarial, el art. $145^{\circ}$ del mismo cuerpo normativo enunciado, declara lo siguiente: "El notario es responsable, civil y penalmente de los daños y perjuicios que, por dolo o culpa, ocasione a las partes o terceros en el ejercicio de la función.” (Art. 145 del D. L. 1049).

Si bien el Notario Público, tiene una condición y calidad especial, tal y como refiere Ríos Helling, el notario dentro de la Administración Pública ejerce aplicación de la descentralización por colaboración, que es una forma jurídica que se emplea para la realización de las actividades estatales. Afirma pues, que la función notarial es una descentralización por colaboración ya que resuelve los problemas jurídicos, principalmente los relacionados con materia fedante, requiere de sujetos con una preparación técnica especializada; estas personas, en algunos casos, no forman pate directa de la Administración Pública. (...) (Citado por Tambini, Mónica 2014: p. 48)

\subsection{La función objetiva y subjetiva del ejercicio de la función Notarial:}

La responsabilidad notarial, parte de la omisión y/o descuido en las facultades otorgadas a los notarios. Partiendo de dicha premisa, es que podemos dividirla en dos funciones relevantes: 


\subsubsection{Función Objetiva:}

Habiendo desarrollado las características de la Fe Pública, es oportuno mencionar que la principal función objetiva conferida por el estado al notario, es la potestad de dar Fe pública en el momento que formalice una relación jurídica que está debidamente prescrita en la Ley; a su vez el Notario deja constancia de un hecho, situación o trámite no contencioso, legitimando plenamente los negocios que los usuarios le soliciten, en el marco regulado por el cuerpo normativo citado.

En mérito al principio de rogación, es que surgen las pretensiones de las partes, siendo la traducción de estas voluntades, las que quedarán plasmadas en los instrumentos públicos.

\subsubsection{Función Subjetiva:}

La función subjetiva del notario, podemos asociarla a la labor de identificar quienes pueden celebrar actos y de qué forma; en este proceso, resulta importante utilizar los medios electrónicos que por mandato normativo se ponen a disposición de los Notarios, tales como el acceso a RENIEC, la identificación biométrica de huellas dactilares, el Documento Nacional de Identidad. En todo momento el notario tiene el deber informar a las partes, los extremos y trascendencia de los actos celebrados delante de él.

Si bien la función de fe pública es una facultad a título personalísimo del Notario, el artículo 3 del Decreto Legislativo 1049, detalla en su contenido lo siguiente:

“Artículo 3.- Ejercicio de la Función Notarial:

El notario ejerce su función en forma personal, autónoma, exclusiva e imparcial.

El ejercicio personal de la función notarial no excluye la colaboración de dependientes del despacho notarial para realizar actos complementarios o conexos que coadyuven a su desarrollo, manteniéndose la responsabilidad exclusiva del notario”. (El Subrayado es nuestro)

Conforme lo expuesto, ha de considerarse que si bien existe una función Objetiva y Subjetiva en el desarrollo de la función Notarial, resulta oportuno enmarcar la calidad de dependientes del Notario, su responsabilidad y condición jurídica de los mismos en la asunción de responsabilidad frente a terceros. 


\subsubsection{La responsabilidad civil respecto de las funciones atribuidas al dependiente,}

a propósito de las modificatorias propuestas en el artículo 55 de la Ley del Notariado:

La fe de identidad referida en el art. $55^{\circ}$ de la Ley del Notariado, trajo consigo en su redacción original, la existencia de dependientes del Notario a fin de coadyuvar con el desarrollo de sus funciones. Dicho esto, con anterioridad a la promulgación del Decreto Legislativo 1232 (Que modifica diversos artículos, disposiciones complementarias, transitorias y finales del Decreto Legislativo 1049), la redacción original del artículo $3^{\circ}$ y $55^{\circ}$ del mismo cuerpo legal, detallaban en su contenido lo siguiente:

(...)

“Artículo 3.- Ejercicio de la Función Notarial

El notario ejerce su función en forma personal, autónoma, exclusiva e imparcial."

( ...)

“Artículo 55.- Identidad del Otorgante

El notario dará fe de conocer a los otorgantes y/o intervinientes o de haberlos identificado. Es obligación del notario verificar la identidad de los otorgantes o intervinientes, a través del acceso a la base de datos del Registro Nacional de Identificación y Estado Civil -RENIEC-, en aquellos lugares donde se cuente con acceso a Internet y sea posible para la indicada entidad brindar el servicio de consultas en línea, así como a la base de datos de la Superintendencia Nacional de Migraciones, respecto de la información sobre los extranjeros residentes o no en el país, pudiendo acceder al registro de carnés de extranjería, pasaportes y control migratorio de ingreso de extranjeros, para la verificación de la identidad de los intervinientes mediante la verificación de las imágenes, datos y/o la identificación por comparación biométrica de las huellas dactilares. Cuando el notario lo juzgue conveniente exigirá otros documentos y/o la intervención de testigos que garanticen una adecuada identificación.

Para estos efectos, el ejercicio personal de la función no excluye la colaboración de dependientes del despacho notarial, sin que ello implique la delegación de la función para realizar los actos complementarios o conexos que coadyuven al desarrollo de su labor, bajo la responsabilidad exclusiva del notario. (El subrayado es nuestro)

El notario que cumpliendo los procedimientos establecidos en el presente artículo diere fe de identidad de alguno de los otorgantes, inducido a error por la actuación maliciosa de los mismos o de otras personas, no incurre en responsabilidad." Asimismo, el notario público 
deberá dejar expresa constancia en la escritura pública de haber efectuado las mínimas acciones de control y debida diligencia en materia de prevención del lavado de activos, especialmente vinculado a la minería ilegal u otras formas de crimen organizado, respecto a todas las partes intervinientes en la transacción, específicamente con relación al origen de los fondos, bienes u otros activos involucrados en dicha transacción, así como con los medios de pago utilizados."

(...)

En la redacción original de citado artículo 55, podemos realizar un análisis interpretativo, de donde podemos pensar que para el ejercicio de la fe de identidad, tal y como se encuentra redactado; el Notario podrá contar con la participación de dependientes para dichos efectos, situación que resulta contradictoria, toda vez que el acto de Fe, es una facultad personalísima del Notario, no pudiendo ser esta delegada a favor de terceros. Resulta oportuno desarrollar más adelante, la delimitación de los actos complementarios o conexos a los que hace referencia la precitada norma, a favor de los dependientes.

Con la promulgación del Decreto Legislativo $\mathbf{N}^{\circ}$ 1232, publicado el 26 de septiembre del 2015, la disposición del Notario de poder contar con dependientes para coadyuvar al desarrollo de sus funciones, se incorpora dentro del contenido del Art. 3 del D. L. 1049, a su vez el Art. 55 del mismo cuerpo legal, incorpora algunas precisiones y atribuciones al Notario, conforme se detalla:

( ...)

“Artículo 3.- Ejercicio de la Función Notarial

El notario ejerce su función en forma personal, autónoma, exclusiva e imparcial

El ejercicio personal de la función notarial no excluye la colaboración de dependientes del despacho notarial para realizar actos complementarios o conexos que coadyuven a su desarrollo, manteniéndose la responsabilidad exclusiva del notario”.

( ...)

“Artículo 55.- Identidad del Otorgante

El notario dará fe de conocer a los otorgantes y/o intervinientes o de haberlos identificado, conforme a lo siguiente: 
a) Cuando en el distrito donde se ubica el oficio notarial tenga acceso a internet, el notario exigirá el documento nacional de identidad y deberá verificar la identidad de los otorgantes o intervinientes utilizando la comparación biométrica de las huellas dactilares, a través del servicio que brinda el Registro Nacional de Identidad y Estado Civil - RENIEC.

b) Cuando no se pueda dar cumplimiento a lo señalado en el literal a) del presente artículo respecto a la comparación biométrica de las huellas dactilares por causa no imputable al notario, éste exigirá el documento nacional de identidad y la consulta en línea para la verificación de las imágenes y datos del Registro Nacional de Identidad y Estado Civil - RENIEC con la colaboración del Colegio de Notarios respectivo, si fuera necesaria. El notario podrá recurrir adicionalmente a otros documentos y/o la intervención de testigos que garanticen una adecuada identificación.

c) Tratándose de extranjeros residentes o no en el país, el notario exigirá el documento oficial de identidad, y además, accederá a la información de la base de datos del registro de carnés de extranjería, pasaportes y control migratorio de ingreso de extranjeros; en tanto sea implementado por la Superintendencia Nacional de Migraciones, conforme a la décima disposición complementaria, transitoria y final de la presente ley. Asimismo, de juzgarlo conveniente podrá requerir otros documentos y/o la intervención de testigos que garanticen una adecuada identificación.

d) Excepcionalmente y por razón justificada, el notario podrá dar fe de conocimiento o de identidad sin necesidad de seguir los procedimientos señalados en los literales a) y b) del presente artículo. En este caso, el notario incurre en las responsabilidades de ley cuando exista suplantación de la identidad.

El notario que cumpliendo los procedimientos establecidos en los literales a), b) y c) del presente artículo diere fe de identidad de alguno de los otorgantes, inducido a error por la actuación maliciosa de los mismos o de otras personas, no incurre en responsabilidad, sin perjuicio de que se declare judicialmente la nulidad del instrumento.

En el instrumento público protocolar suscrito por el otorgante y/o interviniente, el notario deberá dejar expresa constancia de las verificaciones a las que se refiere el presente artículo o la justificación de no haber seguido el procedimiento."

Si bien el Notario puede contar con la colaboración de dependientes para coadyuvar con el desarrollo de sus funciones, es importante realizar un breve análisis de los artículos antes citados, toda vez de entender quienes pueden ser dependientes del notario y cuál es la naturaleza de la responsabilidad por su intervención; a propósito de la eximente de 
responsabilidad establecida en el art. 55 de la Ley del notariado, logrando definir los límites de su representación dentro de la función notarial y la forma y modo en la que la estructura del artículo pre citado, dispone que los dependientes pueden realizar actividades complementarias o conexas.

Conforme lo antes expuesto, resulta oportuno desarrollar en primer lugar lo dispuesto en el Art. 165 "Presunción legal de representación”, que es desarrollado por nuestra doctrina de la siguiente manera:

"Artículo 165.- Se presume que el dependiente que actúa en establecimientos abiertos al público tiene poder de representación de su principal para los actos que ordinariamente se realizan en ellos".

Como refiere Eric Palacios Martínez, nos encontramos ante el supuesto conocido como "representación de hecho", figura que constituye una aplicación del principio de protección y tutela de la confianza ajena, reconocido por nuestro ordenamiento a través de un análisis constructivo de la disciplina negocial específica y cuya operatividad implica una conceptualización que, aunque fuere preliminar, nos permita entrever tanto los requerimientos necesarios para su actuación particular, como los criterios para distinguirlo de otros principios tales como el principio de la apariencia y el de la buena fe. (Citado por Gaceta Jurídica 2013: pág. 724)

\section{- Principio de la apariencia:}

Por dicho principio se comprende que todos los actos realizados por un tercero con otro sujeto, no teniendo la titularidad para hacerlo, es eficaz, tanto como si hubiese sido realizado por su propio titular, para lo cual necesariamente el título de investidura formal que aparenta el sujeto, tiene que transmitir una situación de confianza del tercero.

\section{- Principio de la buena fe:}

Por dicho principio se comprende el deber de las personas en obrar correctamente, como lo haría una persona honorable y diligente. Nuestra legislación la toma en cuenta para cautelar el tráfico jurídico en la circulación de los bienes.

Volviendo a la presunción de representación, PIETROBON, Vittorino (1961) sostiene que el principio de la confianza, en términos estrictos, puede conceptualizarse como aquel que tiende a la protección de un estado de fiducia en un hecho jurídico o, más 
ampliamente en un hecho relevante para la formación de un supuesto concreto apto para modificar situaciones jurídicas, el que notoriamente comprende el negocio jurídico. Cuando un sujeto ocupa una posición que, según las circunstancias hace deducir a los terceros que se encuentra legitimado para actuar en representación de una empresa, es obvio que ello genera una fiducia en los eventuales clientes por las operaciones cotidianas que aquella desarrolla; fiducia (confianza) que debe ser protegida por el ordenamiento a fin de tutelar, en este caso, indirectamente la seguridad del tráfico jurídico. (pág. 255)

LOHMAN LUCA DE TENA, Guillermo (1994) sostiene que el dependiente entonces debe ser conceptuado como cualquier sujeto que ocupa una posición en un establecimiento abierto al público, situación que genera una confianza en los terceros interesados en torno a su legitimación para vincularse a través de actos que constituyen el giro del negocio. En otros términos, el dependiente es la persona al servicio del empresario o principal que por su cargo, labor o función, ostentan aparente y presumiblemente representación del titular de un establecimiento abierto al público, aunque su principal no ejerza actividad tendiente al lucro. (Citado por Gaceta Jurídica 2013: pág. 724)

Por su parte Galgano refiere que la función que desempeña la norma en este aspecto es, superando la mera referencia a la relación orgánica existente que puede o no puede existir, la de permitir un desenvolvimiento negocial eficaz a los sujetos involucrado en la actividad comercial como instrumentos de colaboración del principal. Ello se condice con la idea de que el tercero no tenga que indagar sobre poderes de tales personas, ya que basta para la formación del negocio la actividad objetiva del dependiente ante él. Así debe entenderse que los dependientes a que nos referimos, son calificados porque la función que le es encomendada los coloca en contacto con la clientela ordinaria de la empresa, y porque, su poder deriva del hecho objetivamente considerado de su colocación en la actividad de la empresa, por lo que algunos autores discuten si técnicamente nos encontramos ante un acto de apoderamiento. (Citado por Gaceta Jurídica 2013: pág. 724)

Dicho esto, debemos entender que el dependiente en sentido estricto, como refiere Eric Palacios Martínez, debe entenderse como aquel sujeto que tiene una relación negocial de servicio que lo vincula en el desempeño de sus funciones, por lo que no necesariamente se requerirá de un contrato de trabajo. 
La doctrina ha señalado que la presunción de representación del dependiente en los locales abiertos al público tiene el carácter iuris et de iure, por lo que su interpretación no admite prueba en contrario, no interpretar ello; generaría inseguridad en las relaciones jurídicas en la protección y tutela de la confianza ajena.

Por todo lo expuesto, concluimos que las características del dependiente reguladas en el artículo 165 pre citado, están orientadas en los siguientes presupuestos:
a. Ejerza funciones en un local abierto al público.
b. Exista relación de subordinación entre el principal y el agente.
c. Recibir una orden de su principal.
d. No exista poder visible.
e. Generar expectativa de confianza.

Dentro de los actos de representación, podemos desarrollar también lo establecido en el artículo $1981^{\circ}$ del Código Civil, cuyo contenido refiere que "Aquel que tenga a otro bajo sus órdenes responde por el daño causado por éste último, si ese daño se realizó en el ejercicio del cargo o en cumplimiento del servicio respectivo. El autor directo y el autor indirecto están sujetos a responsabilidad solidaria”.

Juan Espinoza (1998) declara que para la responsabilidad civil (...) derivada del obrar de sus administradores o sus representantes y de sus dependientes. Aquí debe tenerse en cuenta los actos o negocios de gestión y los actos ilícitos (p.196).

Como refiere el mismo autor, este supuesto puede ser abordado desde el punto de vista de la responsabilidad civil y desde el de la ineficacia. Con referencia al primer aspecto, los modelos jurídicos que resuelven este problema no son uniformes. La orientación actual de la jurisprudencia francesa (de cuyo Code civil nace el modelo jurídico de responsabilidad del principal) es restrictiva, porque excluye la responsabilidad en caso de abuso y de interés personal del dependiente; pero la admite en caso en el cual éste ha podido producir daño con los medios suministrados por el principal y los terceros que hubieran estado en grado de creer que éste actuaba en el ámbito de sus funciones. (p.739).

Sin perjuicio de lo antes enunciado, es importante considerar para el supuesto de responsabilidad civil indirecta, los requisitos legales especiales, tales como el que (i) exista una relación de dependencia y/o subordinación fáctica o jurídica con el principal 
y (ii) que el autor directo haya causado el daño en el ejercicio del cargo o en cumplimiento del servicio respectivo. Si bien es necesario identificar los supuestos antes enunciados en cada paso en particular, de identificarse ambos, el efecto jurídico establecido por nuestro ordenamiento jurídico es el de que ambos autores (directo e indirecto) son responsables solidariamente frente a la víctima en atención al principio de protección y tutela de la confianza ajena. Recordemos que responsabilidad indirecta del principal por los hechos del subordinado se fundamenta en la "culpa" (culpa in eligendo e culpa in vigilando). En nuestro ordenamiento jurídico, la ausencia de culpa se deberá analizar como supuesto especial de responsabilidad indirecta, por cuanto el mismo no tiene un sustento exclusivo en la noción de culpa en la elección, sino en el factor de atribución objetivo denominado "garantía de protección de la confianza ajena", mediante el cual el principal respalda y responde por los actos realizados por el denominado representante de hecho.

Si bien hemos delimitado la naturaleza jurídica de los dependientes, conforme lo prevé nuestra doctrina y legislación; resulta oportuno determinar cuáles son las actividades complementarias o conexas que pueden ejercer los mismos, siguiendo con la relación y estudio de la fe de identidad desarrollada en el referido artículo 55 de la Ley del Notariado.

Dicho esto, comenzamos en afirmar que en el contenido del D.L 1049 y su reglamento, no existe un pronunciamiento específico y/o normativo que haga referencia a cuales son las actividades complementarias o conexas que pueden ejercer los dependientes, por lo que corresponderá definir los mismos desde un punto de vista conceptual y la forma en la que es tratado en nuestro ordenamiento jurídico.

La Real Academia española, las define de la siguiente manera:

* Complementario (ria):

De complemento.

\section{1. adj. Que sirve para completar o perfeccionar algo.}

2. adj. Dicho de un número de la lotería primitiva: Que, añadido a otros cinco acertados, forma una combinación a la que corresponde el segundo premio 
El supuesto antes enunciado (Complementario), desde el punto de vista jurídico, pueden verse desarrollado con mayor frecuencia en materia Laboral, por lo que desde este punto de vista, podemos identificar que en materia de intermediación laboral, el Artículo tercero de la Ley 27626, detalla que intermediación laboral sólo procede cuando medien supuestos de temporalidad, complementariedad o especialización, en otras palabras no se puede utilizar la intermediación para ejecutar permanentemente la actividad principal de la empresa usuaria.

Artículo $1^{\circ}$ del Decreto Supremo $N^{\circ}$ 008-2007-TR (Modificación del Artículo $1^{\circ}$ del Decreto Supremo No03-2002-TR), describe como:

- Actividad Principal: Aquella actividad principal de la empresa usuaria aquélla actividad que es consustancial al giro del negocio. Son actividad principal las diferentes etapas del proceso productivo de bienes y de prestación de servicios: exploración, explotación, transformación, producción, organización, administración, comercialización y en general toda actividad sin cuya ejecución se afectaría y/o interrumpiría el funcionamiento y desarrollo de la empresa.

- Actividad Complementaria: Aquélla que es de carácter auxiliar, no vinculada a la actividad principal, y cuya ausencia o falta de ejecución no interrumpe la actividad principal, tal como las actividades de vigilancia, seguridad, reparaciones, mensajería externa y limpieza. La actividad complementaria no es indispensable para la continuidad y ejecución de la actividad principal de la empresa usuaria.

conexo, xa:

Del lat. connexus, part. pas. de connectĕre 'unir'.

1. adj. Dicho de una cosa: Que está enlazada o relacionada con otra.

2. adj. Der. Dicho de varios delitos: Que por su relación deben ser objeto de un mismo proceso.

Por su parte, para el término conexo; tomamos como referencia la jurisprudencia nacional recaída en el Expediente $\mathrm{N}^{\mathrm{o}}$ 02364-2008-PHC/TC LIMA, el mismo que pre supone que la demanda de hábeas corpus, no solo se configura por la protección al 
derecho a la libertad, sino que trae consigo la protección de derechos Constitucionales conexos, tales como pueden ser el derecho al debido proceso y tutela efectiva. Tal es así, que en el pronunciamiento del tribunal, se advierte la admisibilidad del recurso presentado, en atención a la protección y defensa de los derechos constitucionales conexos con la libertad individual.

Dicho esto, debemos entender el término conexo, previo en al análisis de los Derechos Conexos, como aquel que protege los intereses jurídicos de ciertos derechos principales, existiendo una relación directa con el derecho principal invocado. Téngase a cuenta, que como es analizado por los miembros del Tribunal Constitucional, la protección a la privación la libertad individual, no excluye a su vez la protección de proteger otros derechos conexos que promuevan el correcto ejercicio de la legítima defensa.

Sobre lo antes expuesto, resulta oportuno precisar que el Decreto Legislativo 1049, no establece los límites y/o cuales son los actos complementarios y/o conexos que podrían ejercer los dependientes a fin de coadyuvar con el ejercicio de la función Notarial, dicho esto; corresponde realizar un análisis interpretativo, en atención a la conceptualización jurídica de ambos términos, según lo antes desarrollado; de tal forma que podamos estudiar adecuadamente la eximente de responsabilidad establecida en el Art. 55 del D. L 1049, en el ejercicio de la fe de identidad.

Habiendo delimitado la naturaleza jurídica de los dependientes y la interpretación legal para lo que podemos considerar como actos complementarios y/o conexos en nuestra legislación, sin perjuicio de los actos que sean ejercidos por los dependientes en el ejercicio del cumplimiento de las funciones a su cargo, es el caso que la responsabilidad será (en el presupuesto antes enunciado) única y exclusivamente del notario, en atención a que el actuar del representación de hecho, constituye una aplicación del principio de protección y tutela de la confianza ajena, de donde se entiende que el dependiente actúa como si fuese su propio principal, sin perjuicio de ser de manera personalísima quien garantiza la seguridad jurídica por ser quien otorga la Fe Pública.

Por habitualidad, los diversos supuestos de daños a terceros, siempre ha tenido como protagonismo diversos escenarios de falsificación y/o suplantación de personas, motivo por el cual, el Estado en su rol protagónico de velar por la seguridad ciudadana, mediante Ley 30336 se le confiere facultades al ejecutivo a fin de poder legislar en 
materia de seguridad ciudadana, con la finalidad de fortalecer la lucha contra la delincuencia y el crimen organizado. En atención a las facultades antes expuestas, mediante Decreto Legislativo 1232 (Que modifica diversos artículos, disposiciones complementarias, transitorias y finales del Decreto Legislativo 1049), busca mediante su propuesta normativa, garantizar la seguridad jurídica, previniendo la comisión de fraudes y la afectación de derechos de terceros; previniendo y enfrentando las diversas modalidades de fraude en la expedición de instrumentos públicos notariales. La constante habitualidad de la delincuencia en las distintas modalidades de fraude a través de la falsificación documentaria o suplantación de identidad en determinados procedimientos notariales, fue de motivación para que mediante la nueva propuesta normativa se mejoren los mecanismos de control en la expedición de instrumentos públicos notariales protocolares y extra protocolares, tal es así que hemos tenido como estudio del presente trabajo, dicha redacción normativa, a fin de identificar la necesidad de establecer precisiones en la intervención de los dependientes del Notario, quienes por habitualidad y costumbre ejercer funciones personalísimas del Notario que no se les han sido atribuidas.

La propuesta normativa del artículo 55 del mismo cuerpo legal, está orientado a reestructurar la modalidad de uso de los mecanismos electrónicos, como soporte y respaldo en el otorgamiento de la Fe Pública del Notario, manteniendo en su contenido la eximente de responsabilidad del mismo, siempre que haya sido inducido a error, pero a su vez, precisando que solo operará dicha condicionante, siempre que previamente se demuestre el cumplimiento de las disposiciones establecidas en los incisos a, b y c; escenario que desarrollaremos más adelante.

Habiendo desarrollado la naturaleza jurídica del dependiente, es el caso precisar además que corresponde al principal, supervisar y controlar el cumplimiento de las funciones del subordinado. El traslado de responsabilidad del Notario en la intervención de dependientes a su cargo, está orientada a la naturaleza personalísima, autónoma, exclusiva e imparcial que tiene para con los particulares, sin perjuicio de la representación de hecho que los mismos ejercen y que ya hemos desarrollado con anterioridad. 
Resulta oportuno delimitar el rol protagónico entre el Notario Público y la intervención de sus dependientes, en atención a las facultades que le son conferidas a cada uno, de tal forma que cuando se analicen los supuestos de responsabilidad y/o daño, objetivamente podremos aplicar los criterios eximentes de responsabilidad que se encuentran detallados en el artículo materia de análisis.

Tal y como hemos hecho referencia, la responsabilidad del principal como consecuencia del actuar de su dependiente, no solo se ve regulada en el artículo 1981 del C.C.; si no también por el artículo 165 del C.C., el cual refiere que el dependiente que actúa en establecimientos abiertos al público tiene poder de representación de su principal para los actos que ordinariamente se realizan en ellos. Dicho esto, corresponde enunciar la función personalísima del Notario en contraposición con los actos complementarios y/o conexos que realizan los dependientes. Dicho esto, corresponde retomar o establecido en el artículo $4^{\circ}$ del Reglamento de la Ley del Notariado, el cual refiere:

(...)

Artículo $4^{\circ}$.- De la definición

El notario es el profesional del derecho encargado, por delegación del Estado, de una función pública consistente en recibir y dar forma a la voluntad de las partes, redacta los instrumentos adecuados a ese fin, les confiere autenticidad, conserva los originales y expide traslados que dan fe de su contenido. Su función también comprende la comprobación de hechos y la tramitación de asuntos no contenciosos previstos en las leyes de la materia. (EI subrayado es nuestro)

El notario no es funcionario público para ningún efecto legal. ( ...)

Dentro de los instrumentos Notariales, estos se dividen en dos:

\section{Instrumentos Protocolares}

- Escrituras Públicas

- Actas de Tranferencias Vehicular

- Asuntos No Contenciosos

- Testamentos

- Diligencia de Protesto 


\section{Instrumentos Extra Protocolares}

- Certificación de Firmas

- Certificación de Reproducciones

- Certificado de Supervivencia

- Copias Certificadas

- Autorización Viaje Menores

- Legalización de Apertura de Libros

- Poderes Fuera de Registro y Otros Especiales

- Certificación de Entrega de Cartas Notariales

Sin perjuicio de la responsabilidad del Notario por hecho del dependiente ya desarrollada con anterioridad, téngase a cuenta que el principal tiene a su vez una responsabilidad indirecta del principal por los hechos del subordinado en atención de la culpa in eligendo, que responde no por el sustento exclusivo en la noción de culpa en la elección, sino en el factor de atribución objetivo denominado "garantía", mediante el cual el principal respalda y responde por los hechos de sus dependientes. Bajo dicha premisa garantista, es que el referido artículo 1981 del C.C., que precisa que aquel que tenga a otro bajo sus órdenes responde por el daño causado por éste último, si ese daño se realizó en el ejercicio del cargo o en cumplimiento del servicio respectivo. El autor directo y el autor indirecto están sujetos a responsabilidad solidaria

Juan Espinoza (2016) Detalla que la presunción establecida en el artículo enunciado precedentemente, tiene carácter iuris et de iure, vale decir, no admite prueba en contrario, toda vez que es el principal quien libremente ha tomado la elección de los dependientes que coadyuven con el desarrollo de sus funciones. No hacer esta interpretación generaría inseguridad en las relaciones jurídicas, toda vez que no existiría la denominada "garantía", en el actuar de los dependientes que actúan a nombre de su principal.

Para la doctrina argentina Matilde M. (1980), dentro de los fundamentos de la responsabilidad, plantea las siguientes teorías:

A). Teoría de la culpa "in eligendo" o "in vigilando": Los defensores de los principios subjetivistas, temerosos de su quiebra, han recurrido en este ámbito para sustentar la responsabilidad inexcusable del patrón de su culpa, al expediente técnico de presumirla 
iuris et de iure, es decir a considerarla presente aunque de hecho esté ausente; $\underline{\text { el }}$ principal sería entonces responsable por haber elegido mal o vigilado

deficientemente a sus subordinados, pero sin poder demostrar lo contrario, porque como declara Llambías, dentro de esta postura: "La presunta culpa del principal ha pasado a ser un hecho abstracto que se estima necesariamente presente en cada caso de responsabilidad directa del dependiente aunque en un hecho concreto no haya ocurrido así”. (Citado por Zabala, Matilde 1980: p. 50)

\section{$(\ldots)$}

La presunción absoluta de culpa encierra simultáneamente la más rigurosa presunción de causalidad. En efecto, siendo la causalidad presupuesto previo a la culpabilidad, es menester suponer que si el patrón es considerado culpable del daño ocasionado directamente de su dependiente, es también su autor (mediato), pero no solo no se le admite la prueba de que obró diligentemente, sino tampoco la más radical de la causa ajena que excluiría a su respecto el nexo causal: aunque la elección del subordinado fuese forzosa o aunque por caso fortuito no hubiese podido vigilarlo, responde igualmente. (p. 50)

B. Teoría del riesgo creado: La teoría del riesgo creado, que cobró gran auge en Francia a fines del siglo pasado para fundamentar objetivamente la responsabilidad patronal para fundamentar objetivamente la responsabilidad por accidentes del trabajo, extendiéndose luego como doctrina general, destaca la insuficiencia de la culpa como principio justificado de la responsabilidad civil, y la radica (en la forma de la teoría que aún mantiene acogida) en la idea de provecho: ibi emolumentum, ibi onus, quien recoge los beneficios de una actividad, debe soportar las cargas inherentes, entre las que se encontrarían los daños causados a terceros por los empleados o dependientes del responsable. (p. 56)

C. Teoría de la representación: La teoría de la representación sostiene que como los agentes o empleados realizan el encargo en nombre y por cuenta del principal, son sus representantes, por lo que él responde como si hubiese obrado personalmente por los ilícitos cometidos en el ámbito de la función.

$(\ldots)$ 
El error esencial de la teoría de la representación radica en un trastrueque de nociones jurídicas con un significado preciso, lo que ha dado pie a las críticas que le han formulado. En realidad, la representación es una institución muy bien delineada, cuyos contornos no puedes ser borrados, y que, no puede ser asimilada a la figura derivada de la relación funcional de dependencia.

D. Teoría del instrumento: (...) La teoría que sustenta con mayor acierto la responsabilidad del principal puede considerarse una derivación de la representación, pero sin sus efectos técnicos, los que se condensan en el empleo deformante del concepto de representación. Sin embargo, encierra esta doctrina algo de verdad y este capital de sentido común es el que puede recogerse. Lo valioso en ella ha sido poner de relieve la identificación externa y funcional que se opera entre patrón y dependiente, la que, no obstante, no debe considerarse como resultado de ser éste representante de aquél pues, como se ha señalado, no es admisible, sino que es producto "hacia afuera" de la relación interna de subordinación que existe con motivo del desempeño de un encargo o una tarea para el principal.

El desarrollo de esta teoría, en efecto, la vinculación jerárquica funcional transciende ante los terceros, dando lugar a un cierta unificación de las figuras del patrón y su encargado, lo que en el marco circunscripto de la función es totalmente exacto: el agente obra en lugar responsable indirecto, que pudiendo haber obrado por sí, obró no obstante por otro $(\ldots)$

El patrón que en lo lícito ve aumentadas sus potencialidades de actuación por el empleo de terceros, debe sufrir las derivaciones que ocurran en lo ilícito. (p. 63)

La presente teoría adquiere un mayor acierto, considerando que la actuación del dependiente en establecimientos abiertos, presupone la existencia de poder de representación de su principal para los actos que ordinariamente se realizan en ellos, tal y como lo refiere el artículo 165 del C.C. antes enunciado, no admitiendo prueba en contrario.

Juan Espinoza (2016) detalla que el supuesto de responsabilidad "con ocasión" de las funciones, si bien fuertemente criticado (como lo hemos visto) por un importante sector de la doctrina argentina, ha ido abriéndose paso a nivel jurisprudencial. Ello en atención al hecho que al acto generador del daño ha tenido origen en este particular status_del agente que produjo daño (en calidad de titular del órgano, representante o dependiente 
de la persona jurídica), o dicho en otras palabras de no haber mediado status, tal daño no se hubiera producido. El dato de la experiencia jurisprudencial no debe ser pasado por alto, por cuanto éste constituye un indicador de los problemas sociales que afectan a un grupo humano y por ello que, no obstante las críticas doctrinarias, en el Proyecto del Código Civil de la República Argentina, presentado por la comisión Honorara designada por decreto del Poder Ejecutivo Nacional $\mathrm{N}^{\circ}$ 685/95, con fecha 18.12.98, se conserva el supuesto de hecho de responsabilidad civil con ocasión de las funciones. (p. 753)

En materia de responsabilidad del dependiente, la legislación argentina cuenta con mayores precedentes jurisprudenciales, dentro de los cuales resulta oportuno resaltar aquellos relacionados a la objetividad y el ejercicio de funciones del dependiente, en contraste con el daño provocado a terceros, como consecuencia de la ejecución de su cargo y/o en el abuso de las facultades que les son conferidas. Como lo ha referido Juan Espinoza (2000) La jurisprudencia argentina, paulatinamente ha ido delineando los contornos de la responsabilidad civil con ocasión de las funciones. La Cámara Nacional Civil, Sala G, con fecha 10.04.86, define este supuesto de hecho (a propósito del hecho del dependiente) de la siguiente manera:

"dentro de la 'ocasión' a la que alude el art. 43 del Código Civil sólo quedan comprendidos aquellos actos ajenos o extraños a la función, pero que únicamente pudieron ser llevados a cabo por el dependiente en tal calidad y por mediar esas funciones".

En sentido excluyente, respecto de los actos in itinere, la Cámara Nacional Civil, Sala C, con fecha 27.06.74, estableció que:

"no corresponde considerar que el evento dañoso ocurrió con motivo o con ocasión de las funciones de un dependiente de la empresa codemandada, si quien manejaba el vehículo era empleado administrativo de la misma y no conductor de camiones y el hecho tuvo lugar fuera de su horario de trabajo".

Caso típico de la responsabilidad con ocasión de las funciones es el del dependiente que ha cometido un ilícito (generalmente penal) con las personas con las cuales contacta a propósito del ejercicio de sus funciones. Así, la Cámara Nacional Civil, Sala F, con fecha 20.05.77, determinó que: 
"la cláusula de irresponsabilidad impresa en un ticket de estacionamiento por los daños y perjuicios por robo, incendio o cualquiera otra causa no puede invocarse cuando se trata no de daños causados por terceros sino por el hecho ilícito cometido por un dependiente, en ocasión del desempeño de sus funciones, y cuya responsabilidad reparadora alcanza al principal, siendo, por lo tanto, indiferente definir la naturaleza de la relación jurídica que vinculaba (contrato atípico), pues cualquiera sea el criterio con que se lo enfoque, lo que prevalece siempre es la obligación de restituir la cosa en el mismo estado en que fue entregada, salvo caso fortuito o fuerza mayor".

En este grupo de casos, también se encuentra el que decidió la Cámara Nacional Civil, respecto de un disparo mortal realizado por un dependiente, con fecha 10.04.86, ya citado, sancionando que:

"Debe responder la provincia de Buenos Aires por la muerte de un individuo ocurrida como consecuencia del balazo (...) disparado por una agente perteneciente a la fuerza policial de aquella provincia. La responsabilidad del principal surge del hecho de que el daño se produjo con ocasión de las funciones del dependiente (conf. arts. 43 y 1113, parte 1, Código Civil). Debe, asimismo, responder en forma concurrente el agente policial que efectuó el disparo (en el caso, el policía se hallaba franco de servicio, sin uniforme y con el arma de la repartición, que tenía el deber de portar)".

Siguiendo con este grupo de supuestos, el Juzgado de Primera Instancia Rawson (Chubut), con resolución del 20.04.94, resolvió el caso de un recluta que realizaba el servicio militar obligatorio, que recibió un disparo mortal de otro, durante la guardia que realizaba, de la siguiente manera:

"a pesar de que la actitud del dependiente implique una desobediencia a las instituciones dadas o a los reglamentos y hasta un abuso de incumbencia, el Estado ante el hecho dañoso cometido por éste, debe responder, porque la función o ha facilitado grandemente la comisión del acto, o ha sido motivo o la ocasión para cometerlo. Es decir que la responsabilidad del principal se extiende, no sólo por los actos realizados por el dependiente en estricto cumplimiento de las tareas encomendadas, sino cuando el daño se ha producido por hechos realizados en el desempeño de la función o, en otros términos, 
cuando el hecho que resulta extraño a la función únicamente ha podido llevarse a cabo por el dependiente en tal calidad y no hubiera podido realizarse de no mediar dicha función".

También se presenta la responsabilidad civil con ocasión de las funciones, cuando un funcionario despide a un dependiente, no siendo esta facultad de su competencia. Por ello, la Cámara Primera en lo Civil y Comercial de Bahía Blanca, Sala II, con fecha 29.11.84, prescribió que:

"aun admitiendo que la conducta del intendente municipal fue irregular o ilícita, es indudable que actuó en su función de tal, al separar del cargo al agente y negarle indemnización, en el ejercicio de actos administrativos que le incumbían y le competían, y en ocasión de sus funciones y no fuera del ejercicio de su función. No se trata, en el caso, de un hecho que denote 'al hombre en sus debilidades, sus pasiones, sus imprudencias; no se advierte una intención delictual en el funcionario, en cuyo caso sería necesaria una condena previa en sede penal para abrir el camino a una reparación personal de orden civil. Por ende la pretensión resarcitoria debe dirigirse contra la comuna".

La resolución de fecha 10.04.86 de la Cámara Nacional Civil, ya comentada, da por finalizado el problema de la pretendida dualidad de regímenes de los arts. 43 y 1113, al explicar que:

"resulta posible extender el criterio normativo del art. 43 del Código Civil, por aplicación analógica, a la responsabilidad del principal por el hecho ilícito de sus dependientes, atento la notoria similitud de las situaciones contempladas en dicho artículo y el 1113, parte 1 del mismo código, en efecto, no caben distingos entre la responsabilidad 'directa' de la persona jurídica por los actos de gestión de los integrantes del órgano y la 'indirecta' que emerge del actuar de los dependientes, en punto a que en ambos supuestos, aquella ha de responder por los hechos cometidos por estos 'en ejercicio' o 'con ocasión' de las funciones ya se trate de la conducta de unos u otros, la persona jurídica tiene que soportar las consecuencias de los actos realizados por estos últimos en el círculo de las funciones que se les asignara". (p.25)

Tal y como podemos observar, la doctrina nacional y extranjera comparten y precisan claramente conforme lo expuesto, que aún en la intervención y disposición de 
dependientes, siempre el principal responde por los daños causados a terceros, en primera instancia por la sola responsabilidad de no saber elegir y consecuentemente por el tipo de daño que se haya causado. El atenuante de la responsabilidad del principal, se direcciona en la premisa que el dependiente haya actuado en un ejercicio ilimitado de las funciones conferidas, cuyo actuar negligente traiga consigo el daño y/o perjuicio a terceros.

\subsection{Responsabilidad Civil del Notario:}

En la actualidad, la gran demanda de los servicios notariales no es ajena a sufrir las consecuencias de la criminalidad, muchas veces perjudicando estos a terceros no involucrados en una relación jurídica y hasta al propio Notario por no haber tenido la diligencia y el cuidado frente a la presentación de documentos fraudulentos y/o a la suplantación de personas.

En la naturaleza Civil, existirá un deber de reparación por los daños causados a los particulares, sea provocada por dolo o culpa.

- Dolo: Facultad atribuida a la intención, actitud. El que comete una acción con la intención de dañar.

- Culpa: Facultad atribuida de la casualidad y/o al incumplimiento de obligaciones, omitiendo aquellas diligencias exigidas por mandato legal para evitar un daño sobreviviente.

\subsection{Responsabilidad Civil Extracontractual del Notario, apropósito de la} intervención de sus representantes de hecho, como hecho personalísimo del mismo:

En la Responsabilidad extracontractual, tenemos 2 escenarios regulados y detallados en los Art. 1969 y 1970, que precisan lo siguiente:

Artículo 1969.- Aquel que por dolo o culpa causa un daño a otro está obligado a indemnizarlo. El descargo por falta de dolo o culpa corresponde a su autor. 
Artículo 1970.- Aquel que mediante un bien riesgoso o peligroso, o por el ejercicio de una actividad riesgosa o peligrosa, causa un daño a otro, está obligado a repararlo.

La responsabilidad extracontractual no se basa en el origen de un vínculo contractual, sino en una potestad conferida por ley. Es por ello que nuestro propio ordenamiento jurídico, a través del principio de autonomía de la voluntad, no da la libertad de contratar y de contratación, eligiendo a la parte con la que contrataremos y detallando el contenido de la relación contractual a formalizarse. "La autonomía privada posee un doble contenido, la libertad de contratar o facultad de decidir con quien, como y cuando contratar, y la libertad contractual y configuración interna, (...)” (Cas. Nro. 280-2000Ucayali; El Peruano; 25-08-2000; p. 6100)

La Ley detalla que el Notario prestará sus servicios profesionales a cuantas personas lo requieran, salvo las excepciones señaladas por ley, el reglamento y el Código de ética. (Inc. c del art. 16 del D. L. 1049)

Este tipo de responsabilidad se produce cuando la existencia del daño es causado no sólo a las partes otorgantes, sino también a terceros beneficiarios del acto o negocio. Para lo cual es necesario poder probar el nexo causal entre el actuar y el daño causado, con el actuar culpable o negligente.

Respecto del daño provocado por la intervención de dependientes con causa del ejercicio de las funciones que les fueren conferidas, es oportuno precisar que como y se desarrolló en puntos anteriores, la denominada "Presunción legal de representación", es conocida por nuestra doctrina como "representación de hecho", figura que constituye una aplicación del principio de protección y tutela de la confianza ajena, de donde el Notario responde personalmente, en atención al poder de representación que ostenta su dependiente, en establecimientos abiertos al público.

\section{5. ¿El artículo 55 de la Ley del Notariado, una eximente de responsabilidad?:}

La redacción del artículo 55 pre citado, establece literalmente que:

"El notario dará fe de conocer a los otorgantes y/o intervinientes o de haberlos identificado, conforme a lo siguiente: 
a) Cuando en el distrito donde se ubica el oficio notarial tenga acceso a internet, el notario exigirá el documento nacional de identidad y deberá verificar la identidad de los otorgantes o intervinientes utilizando la comparación biométrica de las huellas dactilares, a través del servicio que brinda el Registro Nacional de Identidad y Estado Civil - RENIEC.

b) Cuando no se pueda dar cumplimiento a lo señalado en el literal a) del presente artículo respecto a la comparación biométrica de las huellas dactilares por causa no imputable al notario, éste exigirá el documento nacional de identidad y la consulta en línea para la verificación de las imágenes y datos del Registro Nacional de Identidad y Estado Civil - RENIEC con la colaboración del Colegio de Notarios respectivo, si fuera necesaria. El notario podrá recurrir adicionalmente a otros documentos y/o la intervención de testigos que garanticen una adecuada identificación.

c) Tratándose de extranjeros residentes o no en el país, el notario exigirá el documento oficial de identidad, y además, accederá a la información de la base de datos del registro de carnés de extranjería, pasaportes y control migratorio de ingreso de extranjeros; en tanto sea implementado por la Superintendencia Nacional de Migraciones, conforme a la décima disposición complementaria, transitoria y final de la presente ley. Asimismo, de juzgarlo conveniente podrá requerir otros documentos y/o la intervención de testigos que garanticen una adecuada identificación.

d) Excepcionalmente y por razón justificada, el notario podrá dar fe de conocimiento o de identidad sin necesidad de seguir los procedimientos señalados en los literales a) y b) del presente artículo. En este caso, el notario incurre en las responsabilidades de ley cuando exista suplantación de la identidad.

El notario que cumpliendo los procedimientos establecidos en los literales a), b) y c) del presente artículo diere fe de identidad de alguno de los otorgantes, inducido a error por la actuación maliciosa de los mismos o de otras personas, no incurre en responsabilidad, sin perjuicio de que se declare judicialmente la nulidad del instrumento.

En el instrumento público protocolar suscrito por el otorgante y/o interviniente, el notario deberá dejar expresa constancia de las verificaciones a las que se refiere el presente artículo o la justificación de no haber seguido el procedimiento."

Claramente, entendemos que la facultad fedante, es única y exclusivamente atribuida a el Notario, visto que el presente artículo de manera imperativa, detalla que (...) $\underline{E l}$ notario dará fe de conocer a los otorgantes y/o intervinientes o de haberlos identificado (...), 
sin perjuicio de ello, recordemos que la persona investida del Poder público atribuido por el Estado, es única y exclusivamente el Notario, por lo que dicha actividad no podría considerarse como una facultad complementaria y/o conexa, que pueda ser trasladada a los dependientes del Notario, en ejercicio de coadyuvar con el desarrollo de sus funciones. Téngase a cuenta que para otorgar una correcta fe de identidad de los otorgantes, corresponderá al Notario Público, cumplir íntegramente con las disposiciones detalladas en el Art. 55 pre citado.

En la práctica diaria, vemos que en los oficios Notariales, son los dependientes quienes ejercen muchas veces facultades personalísimas que la propia Ley atribuye única y exclusivamente al Notario. Respecto de la fe de identidad que estamos estudiando en el presente artículo, como ya ha sido referido con anterioridad, inclusive desde su redacción original, antes de la entrada en vigencia del Decreto Legislativo $\mathbf{N}^{\circ} \mathbf{1 2 3 2}$, ya existía una incorrecta interpretación normativa, toda vez que por la estructura del contenido de dicho artículo, se podía pre suponer que el dependiente podría ejercer como acto complementario y/o conexo, la fe de identidad que única y exclusivamente corresponde a el Notario.

Dentro de los tipos de fe Notarial, advertimos en la pre citada norma, la existencia de la fe de identidad y conocimiento, situación mediante la cual "El notario da fe de conocer a los otorgantes y/o intervinientes o de haberlos identificado. Como mecanismo innovador, mediante Directiva DS $\mathbf{N}^{\circ}$ 017-2012-JUS, se da mandato obligatorio del uso del sistema de verificación biométrica de huellas dactilares en todos los oficios notariales del país para el otorgamiento de los instrumentos públicos protocolares y extra protocolares. Paralelamente a ello existen varios convenios entre el Colegio de Notarios de Lima y el RENIEC, mediante la cual los oficios notariales cuentan con el acceso a la información de identidad, de los prestatarios del servicio. Con posterioridad se han promulgado de manera más novedosa e imperativa, el Decreto Legislativo 0062013-JUS, que precisa la obligatoriedad en el uso de los sistemas biométricos, a través de la comparación de las huellas dactilares, cuyo procedimientos y regulación específicas se encuentran detalladas en la Directiva 01-2013-JUS/CM, denominada LINEAMIENTOS PARA LA ADECUADA APLICACIÓN DEL DERETO SUPREMO $\mathbf{N}^{\circ}$ 006-2013-JUS, precisando de manera reiterada, la obligatoriedad en el uso de identificación biométrica, a través de sistemas interconectados con RENIEC. 
El propio Art. 16 de la Ley del Notariado en su inc. i), obliga a los notarios a contar con la infraestructura tecnológica mínima que permita la interconexión con su colegio de notarios, la información que facilite la prestación de servicios profesionales de intercambio comercial nacional e internacional y de gobierno electrónico seguro. En materia de seguridad si el notario lo juzga conveniente, exigirá otros documentos y/o la intervención de testigos que garanticen una adecuada identificación. (Art. 16 del D. L. 1049).

Dicho esto, si bien la norma que tratamos en el desarrollo del presente trabajo de investigación, gira entorno a la fe de conocimiento de los otorgantes, resulta muy importante diferenciar entre conocer a un otorgante y/o haberlo identificado plenamente. En una relación personal entre usuario y el notario, podemos entender que el notario conoce al otorgante por la sola relación de intercambio de información y a la comunicación directa que mantiene con el mismo. Por otro lado, la identificación está orientada como lo han regulado las disposiciones normativas enunciadas en los párrafos precedentes, como el deber del notario de verificar la identidad de la persona, accediendo a los medios electrónicos y/o tecnológicos puestos a disposición del notario y usados en su oficio notarial. En consecuencia son dos situaciones que se desenvuelven a modo independiente, y en donde el notario necesariamente las tiene que diferenciar a fin de poder otorgar la fe de identidad.

Barragán Manuel manifiesta que: "Como se advierte en doctrina "la función característica del notario es la de investir de una presunción de veracidad el acto en que interviene". La fe de conocimiento "no puede significar otra cosa que asegurar la identidad de la persona, o sea, que el nombre, que es el signo con el cual se individualiza, corresponde exactamente al sujeto que se está atribuyendo ese nombre". La fe de conocimiento puede ser de carácter inmediato (cuando es el mismo notario el que conoce al compareciente) o mediato (cuando se vale de testigos, a los cuales conoce el notario personalmente, o cuando recurre a medios supletorios) (p. 11).

Entendiendo que conocer e identificar son las únicas formas de dar fe de la representación que ante el notario comparece, el Dr. Barragan Manuel detalla “(...) En efecto, si entendemos que "identificar a la persona que comparece ante el notario, será en esencia el juicio que éste realiza sobre ciertas bases de hecho, por cuya virtud llega a la conclusión de que determinado nombre es exactamente la representación jurídica de 
quien comparece ante él", lo general es la función del notario de identificar al compareciente: siempre el notario dará fe de la identidad del compareciente. (p.12).

Para la identificación plena de los otorgantes, el inciso b) del artículo 55 antes enunciado, prescribe que el Notario Público podrá recurrir adicionalmente a otros documentos y/o la intervención de testigos que garanticen una adecuada identificación, por lo que resulta necesario considerar lo establecido en el artículo 56 del Decreto Legislativo 1049, el cual refiere que para intervenir como testigo, se requiere tener la capacidad de ejercicio de sus derechos civiles y no estar incurso en los siguientes impedimentos:

a) Ser sordo, ciego y mudo.

b) Ser analfabeto.

c) Ser cónyuge, ascendiente, descendiente o hermano del compareciente.

d) Ser cónyuge o pariente del notario dentro del cuarto grado de consanguinidad o segundo de afinidad; $y$,

e) Los que a juicio del notario no se identifiquen plenamente.

f) Ser dependiente del Notariado.

Al testigo, cuyo impedimento no fuere notorio al tiempo de su intervención, se le tendrá como hábil si la opinión común así lo hubiera considerado.

La intervención de los testigos resulta oportuna y necesaria, siempre que garantice al Notario Público plena efectividad en el otorgamiento de la seguridad jurídica, procurando tener mayor certeza en el otorgamiento de la Fe de identidad de las personas, vale decir asegurar la identidad de la persona, o sea, que el nombre, que es el signo con el cual se individualiza, corresponde exactamente al sujeto que se está atribuyendo ese nombre. Sin perjuicio de lo enunciado, en la práctica; la intervención de testigos para tener mayor certeza de la fe de identidad de los otorgantes, es inaplicable en el Perú, toda vez que si el propio Notario quien otorga la facultad de Fe Pública, tiene dudas de la identidad de un otorgante; no cambiará su percepción por la presencia de uno o más testigos que acrediten lo contrario. 
Siguiendo con el estudio del contenido del art. 55 de la ley del Notariado, de manera excepcional y conforme lo dispuesto en su inciso "d", se deja constancia de lo siguiente:

$(\ldots)$

d) Excepcionalmente y por razón justificada, el notario podrá dar fe de conocimiento o de identidad sin necesidad de seguir los procedimientos señalados en los literales a) y b) del presente artículo. En este caso, el notario incurre en las responsabilidades de ley cuando exista suplantación de la identidad.

$(\ldots)$

En este supuesto excepcional, aplicamos lo desarrollado entorno a la fe de conocimiento, toda vez que en una relación personal entre usuario y el notario, podemos entender que el notario conoce al otorgante por la sola relación de intercambio de información y a la comunicación directa que mantiene con el mismo, por lo que excepcionalmente y por razón justificada, no será necesario seguir los procedimientos indicados en los literales a), b) y c) del artículo 55 pre citado.

Siendo que nuestro estudio está orientado al análisis de la eximente de responsabilidad detallada en el art. 55 del Decreto Legislativo 1049, el cual establece que:

$$
(\ldots)
$$

El notario que cumpliendo los procedimientos establecidos en los literales a), b) y c) del presente artículo diere fe de identidad de alguno de los otorgantes, inducido a error por la actuación maliciosa de los mismos o de otras personas, no incurre en responsabilidad, sin perjuicio de que se declare judicialmente la nulidad del instrumento.

$$
(\ldots)
$$

Dentro del análisis de responsabilidad, objetivamente encontramos que en el considerando antes enunciado, la ruptura del nexo causal opera como eximente de responsabilidad para el Notario, por la intervención y/o hecho de tercero. Sin embargo, consideremos que si para el otorgamiento de fe de identidad, es el dependiente quien ejerce las funciones atribuidas a título personalísimo del Notario, el supuesto de eximente de responsabilidad enunciado, quedaría sin efectos jurídicos, toda vez que ya hemos explicado con anterioridad, que existe una incorrecta interpretación normativa, a 
fin de poder definir cuáles son los actos complementarios y/o conexos que pueden ejercer los particulares; más aún, cuando el propio D.L. 1049 y su reglamento no precisa ni delimita cual cuales son dichas funciones.

Hablar de inducción a error, es tener en cuenta la intención (dolo) del otorgante de querer engañar, situación de donde la rigurosidad probatoria será muy importante, en atención que previamente el notario deberá demostrar haber cumplido con las disposiciones normativas y haber tenido la diligencia necesaria, a fin de lograr identificar plenamente a los otorgantes. No seguir con las disposiciones normativas establecidas en la Ley, es atentar contra la seguridad jurídica, a su vez generar desconfianza en el otorgante afectado, por los costos que se pudieren generar producto de la falsificación e inestabilidad en las relaciones jurídicas.

El error se encuentra regulado dentro de los vicios de la voluntad en el Libro II de nuestra Legislación Civil, por lo que brevemente realizaremos un breve análisis normativo:

Vicios de la Voluntad:

\section{- $\underline{\text { Error }}$}

- Dolo

- Violencia Física

- Intimidación

Ramirez Fernando (2016), detalla que el error es un factor perturbador inconsciente que distorsiona el proceso formativo de la voluntad jurídica, ya en el aspecto relativo a la voluntad interna, en cuyo caso se configura el denominado error-vicio, o ya en lo que se refiere a la exteriorización de la voluntad interna, en cuyo caso se configura el denominado error en la declaración, que el Código Civil legisla claramente diferenciados en el articulado pero bajo el título común de vicios de la voluntad. (pág. 209)

Dentro de la clasificación del denominado error vicio, tenemos los siguientes tipos, según su clasificación:

* El error esencial:

El error esencial es cuando es determinante en la formación de la voluntad interna e induce al sujeto a la celebración del acto jurídico mediante una manifestación de voluntad que no va a ser correlativa a los efectos queridos, o, en otras palabras, el error 
es esencial cuando de no haber mediado el sujeto no hubiera celebrado el acto jurídico. Esencial es, por consiguiente, como precisa PIETROBON, todo error que impide el exacto conocimiento de los efectos del negocio nacido al mundo jurídico. (pág. 213)

* El error indiferente:

El error es indiferente por contraposición al error esencial, porque es el que no ha incidido en la formación de la voluntad interna y, por tanto, no se ha constituido en razón única o determinante de la celebración del acto jurídico. Se le denomina también error accidental. (pág. 214)

* El error de hecho:

El error de hecho o error facti, consiste en la ausencia de conocimiento o en el conocimiento equivocado que recae en cualquier clase de objetos, en su sustancia o en sus cualidades esenciales, así como en las personas o en sus cualidades, en una operación de cálculo o en la apreciación de una cantidad, o en el motivo mismo que induce a la celebración del acto jurídico. La contraprestación de su concepto viene a ser, por ello, sumamente lata pues solo excluye a lo que sea una norma jurídica, que viene a ser el error de derecho.

El error de hecho puede ser esencial o indiferente, según pueda o no servir o no de causal para la anulación del acto jurídico. (pág. 215)

- El error de derecho:

El error de derecho es la ausencia de conocimiento o el conocimiento equivocado referido a una norma jurídica y, por ello, tiene un ámbito de aplicación específico que lo diferencia sustancialmente del error de hecho, según criterio que viene desde el derecho romano. (pág. 228)

Nuestro ordenamiento jurídico, conforme al poder público que otorga al Notario, establece como única facultad exclusiva del mismo, la acción de Fe Pública sobre los actos que se formaliza delante de él; por lo que todos aquellos actos complementarios a dicho acto, podrían trasladarse a ser ejecutados por sus dependientes. Como ya hemos estudiado con anterioridad, esta representación de hecho se encuentra regulada por el artículo 165 del C.C., el cual refiere que el dependiente que actúa en establecimientos abiertos al público tiene poder de representación de su principal para los actos que ordinariamente se realizan en ellos. Dicho esto, la ejecución de los actos del 
dependiente en cumplimiento de las funciones a su cargo, presuponen que han sido efectuadas con conocimiento de su principal, salvo que su actuar fuese fuera del alcance de las funciones que se les fueran conferidas.

En el estudio de la eximente de responsabilidad notarial, téngase a cuenta que previamente establece el cumplimiento de los incisos "a", "b" y "c" antes descritos, de donde podemos advertir que previamente, se han utilizado adecuadamente el uso de los medios electrónicos, de tal forma que el Notario tenga certeza de haber otorgado una correcta fe de Identidad, visto y considerando que la identificación está orientada como lo han regulado las disposiciones normativas enunciadas en los párrafos precedentes, como el deber del notario de verificar la identidad de la persona, accediendo a los medios electrónicos y/o tecnológicos puestos a su disposición y usados en su oficio notarial. Bajo este supuesto personalísimo que la propia ley prevé, no es posible que dicha facultad pueda considerarse como un acto complementario, por lo que de ninguna manera podrán ser ejecutados por los dependientes del Notario. Bajo este supuesto, vemos que frente a la costumbre de poder deber de los dependientes, en el otorgamiento de fe pública, quebranta la categoría eximente de responsabilidad detallada en el artículo 55 del D. L. 1049, convirtiendo este extremo en ineficaz para su ejecución, por la falta de limitaciones y/o precisiones en establecer claramente cuáles pueden ser dichos actos complementarios y/o conexos.

Habiendo desarrollado que entiende nuestra legislación por actos complementarios y/o conexos, aun cuando la ruptura del nexo causal para la eximente de responsabilidad se hubiese perfeccionado por la intervención del hecho de un tercero, la ineficacia de la dicho presupuesto está orientado a la intervención del dependiente, quien al ejercer un acto que no puede ser factible considerarlo como complementario a la función Notarial, incumple la disposición imperativa de la norma que prevé que es el notario quien dará fe de conocer a los otorgantes y/o intervinientes o de haberlos identificado. Dicho esto, aun cuando se hubiesen cumplido los presupuestos establecidos en los literales a), b) y c) del referido artículo $55^{\circ}$, la ineficacia de dicha eximente sería exactamente la misma.

Conforme lo desarrollado en los párrafos precedentes, téngase a cuenta que importante considerar estrictamente el carácter imperativo de nuestra legislación Notarial, por cuanto prevé como requisito fundamental en todo el desarrollo de su cuerpo normativo, 
que el Notario ejerce una función personalísima sobre los actos que se formalicen delante de él, por lo que la imprecisión y falta de regulación especial de las facultades que puedan ser conferidas a favor de sus dependientes, en la práctica diaria, están quebrantando la eximente de responsabilidad del Notario. Téngase a cuenta que dentro del análisis de supuesto de hecho y consecuencia jurídica, la interferencia de los dependientes, juegan un rol muy importante al asumir a título personalísimo actividades "complementarias y/o conexas" cuyo límite de acción no se encuentra plenamente regulada en nuestra legislación, siendo en muchos casos que dichas facultades, correspondieron ser asumidas a título personalísimo por el Notario. 


\section{CONCLUSIONES}

La eximente de responsabilidad atribuida a la ruptura del nexo causal por intervención y/o hecho de tercero, cuyo desarrollo ha sido orientado a lo dispuesto por el artículo 55 de la Ley del Notariado, trae consigo el análisis particular de evaluar de manera especial dicha figura jurídica, toda vez que en la relación de supuesto de hecho y consecuencia jurídica, tenemos la participación de aquellos que coadyuvan al desarrollo de la función Notarial y cuya calidad especial por las funciones atribuidas a su cargo, se suman la representación de hecho que tienen de su principal.

Tal y como hemos desarrollado con anterioridad, el Notario Público adquiere a título personalísimo el poder de fe Pública que le es conferido por el Estado, siendo la única persona que puede formalizar los actos que se celebren delante de él. Por otro lado, este acto de $\mathrm{Fe}$, se encuentra presente en todas las etapas de ejecución de su labor, a consideración que es necesario cumplir con una serie de procedimientos complementarios que garanticen una correcta convicción de formalización de la voluntad de los otorgantes. La intervención de los dependientes en la intención de coadyuvar con el desarrollo de las funciones del Notario, ocupan un rol muy importante, toda vez que la responsabilidad indirecta del principal por los hechos del subordinado, no solo se ejecuta en atención a la presunción legal de representación que ostenta el mismo, sino a su vez por la existencia de la "culpa" (culpa in eligendo), que responde no por el sustento exclusivo en la noción de culpa en la elección, sino en el factor de atribución objetivo denominado "garantía", mediante el cual el principal respalda y responde por los hechos de sus dependientes, siempre que este haya actuado bajo estricto cumplimiento de las funciones a su cargo y por la "culpa" (culpa in vigilando) que corresponde a la labor de supervisión de los actos ejecutados por sus dependientes.

La teoría garantista de responsabilidad, se ve respaldada por aplicación del principio de protección y tutela de la confianza ajena, regulado en el artículo $165^{\circ}$ del C.C., siendo a su vez que complementariamente, artículos como el $1981^{\circ}$ del C.C., precisa que aquel que tenga a otro bajo sus órdenes responde por el daño causado por éste último, si ese daño se realizó en el ejercicio del cargo o en cumplimiento del servicio respectivo. El autor directo y el autor indirecto están sujetos a responsabilidad solidaria. 
Aun cuando hemos determinado plenamente la directa vinculación y grado de responsabilidad del principal en atención al desarrollo de las funciones de sus representantes de hecho, conforme al estudio del presente trabajo de investigación, corresponde indicar que la eximente de responsabilidad establecida en el artículo 55 de la Ley del Notariado, que refiere que "El notario que cumpliendo los procedimientos establecidos en los literales a), b) y c) del presente artículo diere fe de identidad de alguno de los otorgantes, inducido a error por la actuación maliciosa de los mismos o de otras personas, no incurre en responsabilidad, sin perjuicio de que se declare judicialmente la nulidad del instrumento", en el escenario en el que para el otorgamiento de la fe de identidad, haya intervención de un dependiente, este presupuesto adquiere una ineficacia directa e inmediata, toda vez que la facultad de fe pública corresponde a título personalísimo única y exclusivamente a el Notario.

En un proceso investigatorio, en el supuesto de existencia de daño por la inducción a error por parte de un tercero, ni siquiera resultará importante corroborar íntegramente el cumplimiento de los procedimientos previos para una correcta convicción en el otorgamiento de fe de identidad, toda vez que la representatividad de hecho del dependiente en la ejecución de la fe de identidad, no se sustenta jurídicamente en ninguna disposición normativa, toda vez que resulta ser un acto indelegable al corresponder a título personalísimo a el Notario.

Considero viable la existencia de una propuesta normativa que reestructure la redacción del artículo 55 de la Ley del Notariado y/o en su defecto, exista una propuesta normativa en el reglamento de la Ley del Notariado, considerando que si bien el Notario tiene una función personalísima sobre los actos que se formalicen delante de él, el mismo cuerpo legal le otorga la facultad de poder contar con la colaboración de dependientes a fin de poder realizar actividades complementarias y/o conexas a sus funciones, sin embargo; la imprecisión y falta de regulación especial en determinar fehacientemente cuales pueden ser estas facultades conferidas a favor de sus dependientes (en atención a que todas las facultades le son atribuidas al mismo por tratarse de un constante otorgamiento de garantías en la ejecución de la fe pública), en la actualidad quebrantar la eximente de responsabilidad establecida en el artículo 55 pre citado, toda vez que el uso y costumbre en el desarrollo de la función notarial, hace que los dependientes ejerzan facultades de representación de hecho, que no se encuentran sustentadas en un dispositivo normativo, al ejercer facultades indelegables por 
corresponder a título personalísimo, única y exclusivamente a el Notario. Dicho esto, corresponde entender plenamente la importancia del rol de los dependientes, no solo como agentes que coadyuvan a la función principal del Notario, sino a su vez para el correcto tráfico jurídico Notarial y satisfacción de la demanda de los otorgantes. 


\section{REFERENCIAS}

Balotario Desarrollado para los concursos públicos de méritos para el acceso a la función notarial, UBI ALEX Asociados S.A.C. Edición 2013, p. 331 (Colegio de Notarios, 2013)

Barragan, A. M. (1979). Manual de Derecho Notarial. Editorial Temis Librería, Bogotá, Colombia.

Cárdenas, M. (2012). Manual de Derecho Notarial. Jurista Editores.

Castillo, W. (2016). Responsabilidad objetiva de la función notarial: En caso de verificación de la identidad a través de la tecnología biométrica. Revista Diálogo con la Jurisprudencia (pp. 100-111), N²13.

Cas. Nro. 280-2000-Ucayali; El Peruano; 25-08-2000; p. 6100, recuperado del sitio de internet: http://blog.pucp.edu.pe/blog/jorgeraygadasotomayor/tag/nulidad-deacto-juridico/

Decreto Legislativo $\mathrm{N}^{\circ}$ 1049, Ley del Notariado (26 de junio del 2008) Recuperado del sitio de internet en el Ministerio de Justicia https://www.minjus.gob.pe/wpcontent/uploads/2017/04/Decreto-Legislativo-N\%C2\%BA-1049.pdf

Decreto Supremo N ${ }^{\circ}$ 003-2002-TR, Reglamento de la Ley que regula la Actividad de Empresas Especiales de Servicios y de las Cooperativas de Trabajadores.

Decreto Supremo N 008-2007-TR, Modificación del Artículo $1^{\circ}$ del Decreto Supremo Nº03-2002-TR, la Resolución Ministerial N²06-2007-TR, Procedimiento para la Inscripción en el Registro Nacional de Empresas y entidades que realizan Actividades de Intermediación Laboral.

Decreto Supremo N 020-2007-TR, Amplían artículo del Decreto Supremo N0032002-TR referido a la Tercerización de Servicios.

Espinoza Juan, recuperado del sitio en internet: http://dike.pucp.edu.pe/doctrina/civ_art3.PDF

Espinoza Juan (1998). Capacidad y responsabilidad civil de la persona jurídica. Revista Jurídica del Perú. N117, Año XLVIII, octubre-diciembre, pág. 196. 
Espinoza Juan, La responsabilidad civil de la persona jurídica con ocasión de las funciones de sus órganos, representantes y dependientes. Gaceta jurídica $\mathrm{N}^{\circ} 79 \mathrm{~B}$ (jun. 2000) (p. $21-28)$

Espinoza Juan (2016). Derecho de la Responsabilidad Civil (8va. Ed.). Instituto Pacífico S.A.C.

Ramirez Fernando (2016). El Acto Jurídico (10ma Ed.). Instituto Pacífico S.A.C.

Gaceta Jurídica (2003). Código Civil Comentado Tomo I (1era. Edición), pág. 724.

Gálvez, I. y Gonzales J. L. (2014). Manual de Derecho Registral y Notarial (1era. Ed.). Jurista Editores.

Gonzales, G. G. (2016). Derecho notarial: Temas Actuales (2da. ed.). Jurista Editores.

Gutierrez, W. "La Responsabilidad en la Función Notarial" En: "Diálogo con la Jurisprudencia" No 30. Gaceta Jurídica, Lima, Marzo 2001, (pp. 54).

Instituto Nacional de Estadística e Informática (2015). Acceso a las telecomunicaciones. Recuperado de https://www.inei.gob.pe/estadisticas/indicetematico/tecnologias-de-la-informacion-y-telecomunicaciones/

Ley $N^{\circ} 27626$, Ley que regula la Actividad de Empresas Especiales de Servicios y de las Cooperativas de Trabajadores.

Mallqui, M. (2016). La función notarial y su importancia en el Perú. Revista Actualidad Civil (pp. 252-266), $\mathrm{N}^{\circ} 23$.

Matilde M. (1980). La responsabilidad del principal por hecho del dependiente. Editorial Abaco de Rodolfo Depalma S.R.L.

Nuñez, R. (1986). Estudios de derecho notarial, Madrid, Instituto de España, T.I, pp. 14.

Nuñez. P. G. (2014). Comentarios a la ley del notariado (1ra. Ed.). Jurista Editores.

Pietrobon, Vittorino. L'errore nella dotrina del negozio giuridico. Casa Editrice Dott. A. Milani (CEDM). Padova, 1961. (pp. 255). 
Pietrobon, Vittorio, El error en la doctrina del negocio jurídico, Madrid: Revista de Derecho Privado, 1971. Pp. 473.

Puente de la Vega, M. (2007). Protocolo Notarial. Editora Jurídica Grijley.

Reglamento del Decreto Legislativo $\mathrm{N}^{\circ}$ 1049. Recuperado del http://www.academianotarialamericana.org/base/leyes/peru/acceso-a-lafuncion_peru.pdf

Rubio, D. (2015). La suplantación de identidad de los contratantes y la competencia nacional de los Notarios. Revista Gaceta Civil y Procesal Civil, (pp. 77-86) Tomo $\mathrm{N}^{\circ} 23$.

Sotomayor, C. A. (1991). Función Notarial: Concepto e Importancia. En: Derecho Registral y Notarial. Materiales e Enseñanza, Facultad de derecho de a Pontifica Universidad Católica del Perú (pp. 20-31).

Tambini, M. (2014). Manual de Derecho Notarial (3ra. ed.). Pacífico Editores

Villavicencio, M. (2012). Manual del Derecho Notarial. Jurista Editores. 